\title{
Phosphate Glass Fibres and Their Composites
}

Kazi M. Zakir Hossain, Reda M. Felfel, David M. Grant, and Ifty Ahmed

Advanced Materials Research Group, Faculty of Engineering, University of Nottingham, UK

*Corresponding authors: Ifty.Ahmed@nottingham.ac.uk

\section{Table of Contents}

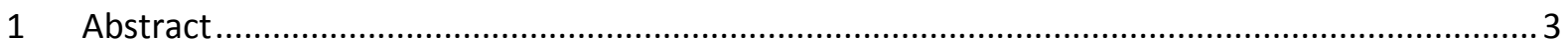

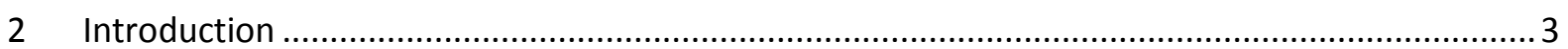

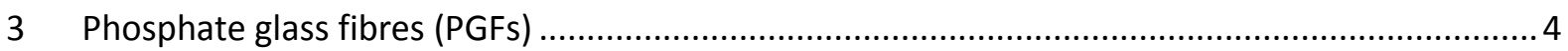

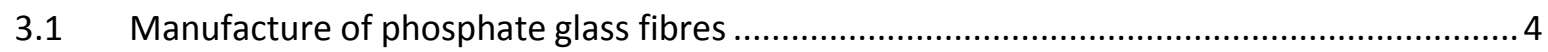

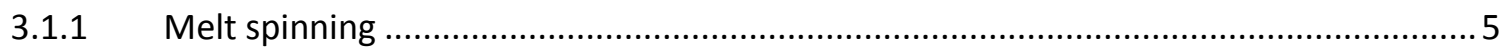

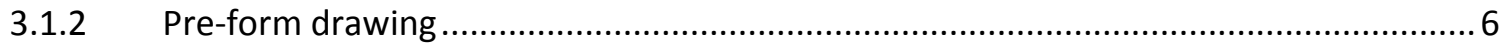

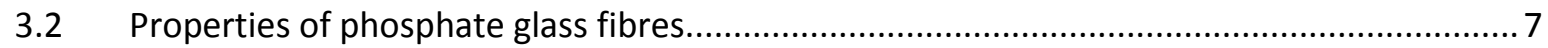

3.3 Biomedical applications of phosphate glass fibres .......................................................... 10

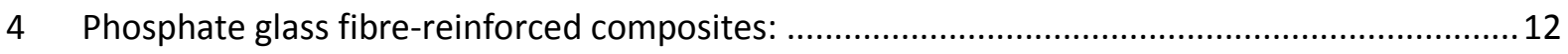

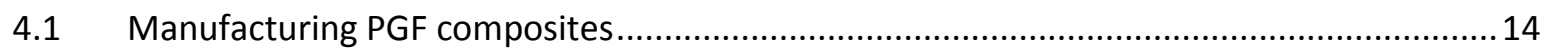

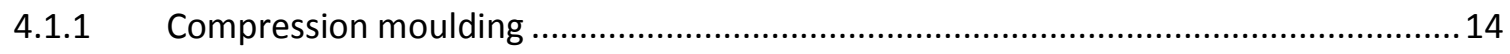

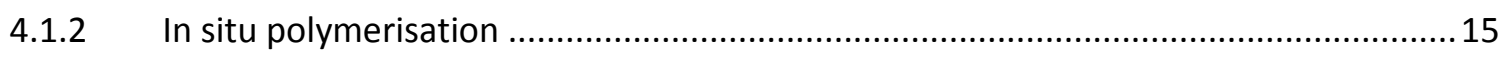

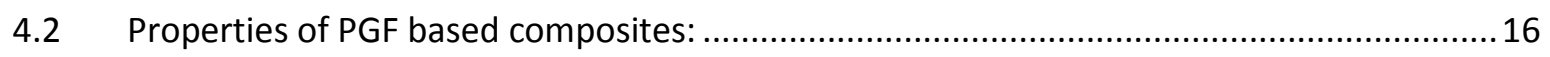

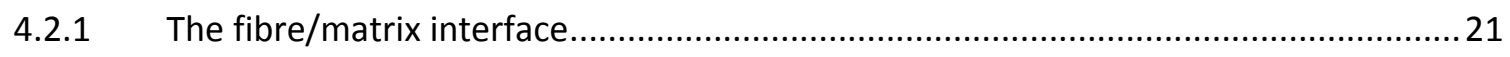

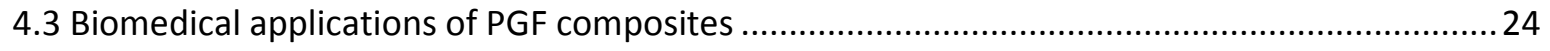

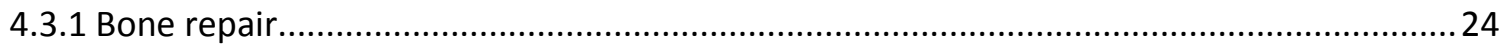

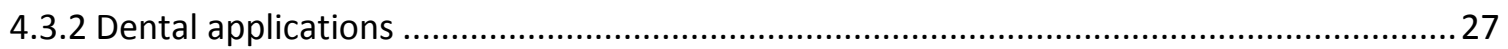

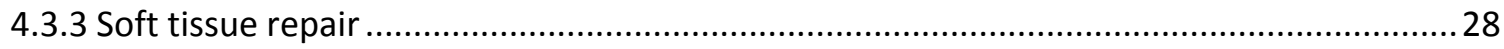

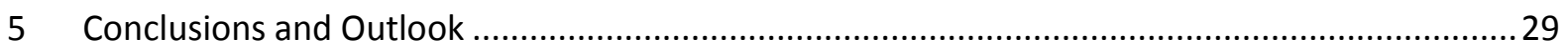

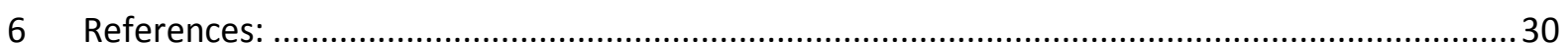


List of abbreviations

PG: Phosphate glasses

PGFs: Phosphate glass fibres

PLA: Polylactic acid

PCL: Polycaprolactone

FRC: Fibre reinforced composites

UD: Unidirectional

RM: Random mat

$\mathbf{V}_{\mathbf{f}}$ : Volume fraction

PBS: Phosphate buffered saline

SBF: Simulated body fluid

HBSS: Hanks buffered saline solution 


\section{Abstract}

An overview of the research conducted utilising phosphate glass fibres (PGFs), their manufacturing processes and utilisation potential for biomedical applications are presented in this chapter. Phosphate glasses of varying compositions in the form of fibrous structures alone and as fibrous reinforcement within composites are discussed. This chapter also highlights the methodologies used for the manufacture of these resorbable glass fibres and their composites. The advantages of using bioresorbable fibres in terms of their mechanical, dissolution, ion release, in vitro and in vivo biocompatibility properties for the replacement, augmentation, guidance and growth of both hard and soft tissue repair applications are also presented.

Keywords: Phosphate glass Fibres, Composites, bioresorbable, biopolymer, tissue engineering.

\section{Introduction}

The interest in use of phosphate glasses (PGs) for biomedical applications has been steadily increasing due to their unique properties, such as their easily controllable degradation profiles coupled with ion release rates, cytocompatibility and mechanical properties ${ }^{1,2}$. The chemical compositions of PGs can be made to resemble the mineral content of bone, which makes them extremely promising candidates for use as resorbable biomaterials and in resorbable implantable devices ${ }^{3}$. PGs have mainly been investigated for applications where only a temporary presence of the implant material is required, thus negating secondary surgical procedures for their removal and enabling the targeted tissue of repair to fully replace the implant in situ. In addition, PGs have been employed in various geometries such as in the form of particles ${ }^{4}$, fibres ${ }^{5,6}$ and microspheres ${ }^{7}$ to enhance their applicability for varying biomedical applications. 


\section{Phosphate glass fibres (PGFs)}

Moving from the bulk glass to fibrous structures, PGFs possess unique advantageous features, such as excellent mechanical properties thus enabling greater reinforcing capability of (bio) polymer matrices and have also been explored as cell guides and soft tissue repair applications. PGs have been fabricated into continuous fibres via both a melt drawing and preform rod manufacturing process and relatively high mechanical properties have been achieved (for example, tensile modulus $\sim 74 \mathrm{GPa}^{8}$ and tensile strength $\sim 1.2 \mathrm{GPa}$ ${ }^{9}$ ). One of the main areas for exploration of phosphate glass fibres (PGFs) has been the manufacture of fully bioresorbable composites as fracture fixation devices ${ }^{10}$ and have also been heavily investigated for fabrication of scaffolds for tissue engineering and regenerative medicine applications ${ }^{5}$.

\subsection{Manufacture of phosphate glass fibres}

PGFs are commonly produced via a melt or pre-form drawing process depending on the fragility index of the glass materials. For instance, comparatively less fragile glasses can be melt drawn and pulled from a solid pre-from to manufacture continuous fibres, whilst highly fragile glasses require rapid quenching of upward drawn fibres processed from a melt ${ }^{11}$. The 'drawing point viscosity' of the phosphate glasses is also very important during fibre production (typically assumed to be $\sim 100 \mathrm{~Pa} \cdot \mathrm{s}^{12}$ ), as these types of glasses are very fragile and prone to crystallise quickly if appropriate conditions are not met. Therefore, the fibre drawing temperature is maintained within a relatively narrow window (which falls below the liquidous melt temperature) so that the melt viscosity can enable continuous fibres to be drawn whilst maintaining their amorphous nature. 


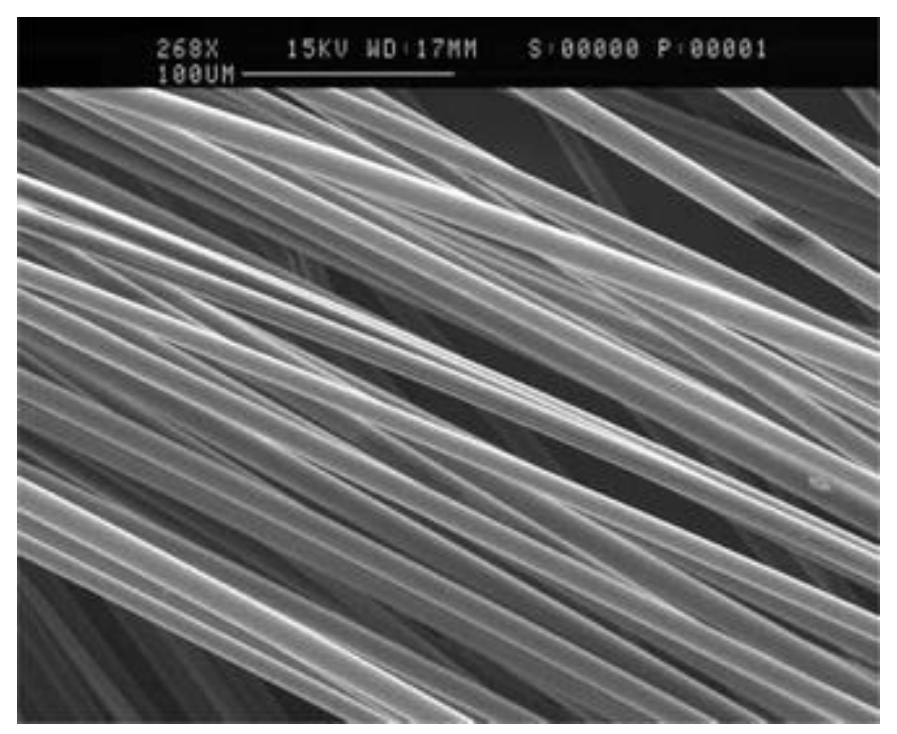

Figure 1: SEM images of typical melt drawn PGFs. Adapted with permission from ${ }^{3}$.

\subsubsection{Melt spinning}

Glass fibres are generally produced via melt spinning techniques which involve melting glass frits in platinum/rhodium crucibles which encompass bushing tips with small holes for the molten glass to flow through gravitationally. Continuous glass fibres are drawn down from the holes and wound onto rotating drums (see Figure 2a). Composition selection of glass materials is also important in order to provide sufficient P-O-P bonds within the molten glass to enable production of continuous fibre. At the same time, stable P-O-P bonds impart the required strength to the fibre to withstand the tensile stresses applied during the drawing process at high temperatures. Fibre properties and dimensions can be controlled via process variables such as, diameter of the bushing exit holes, melt temperature (hence viscosity of the glass), mass flow and drawing speed. In addition, heat treatment (also known as annealing) of the fibres produced is sometimes necessary to relieve internal stresses created within the fibres during the fibre drawing process by reforming P-O-P bonds into more stable configurations ${ }^{13}$. On the other hand, short fibres can also be produced via a melt-blowing technique which is similar to the melt spinning process, except an external force is applied to the molten glass to exit holes and the fibres are cut to required lengths using mechanical means, or air jets (see Figure $2 b$ ). 


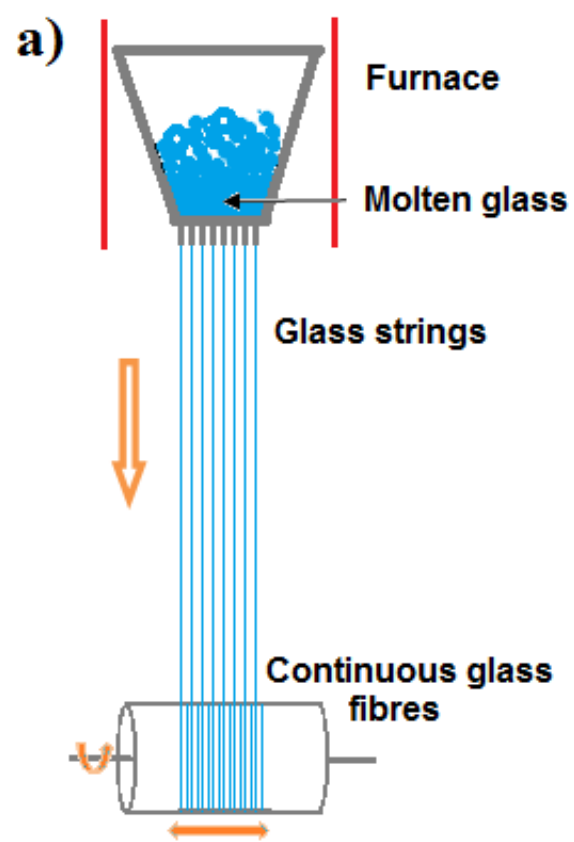

Collector drum b)

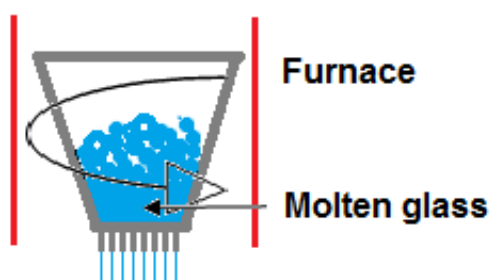

Glass strings

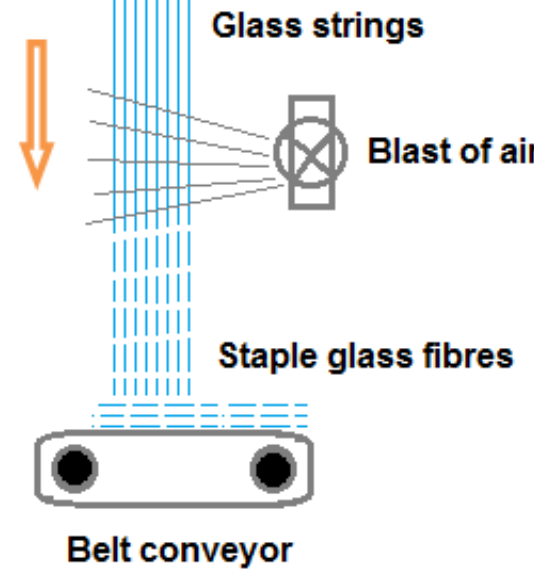

Figure 2: Schematic diagram representing the glass manufacturing processes: a) melt-drawn continuous glass fibres and b) melt-blown staple glass fibres.

\subsubsection{Pre-form drawing}

Glass fibre drawing using the pre-form technique involves two steps: in the first step, a glass pre-form in the form of a rod is produced. This rod can be produced via a glass extrusion process or can be produced via melting the glass and pouring into a pre-form shaped mould 14. In the second step, this glass pre-form is then heated in a furnace above its $T_{g}$ maintaining the viscosity around 4.5-5 Pascal second (Pa s) and allowed to form a gob at the end of the pre-form which falls away from the tip due to gravity. The fibrous strand developed is then wound around and collected on a rotating drum. The fibre properties produced via this technique can also be altered by changing the drawing parameters such as the pre-form heating zone length, heat supplied and the pre-form feed and fibre drawing rates. Recently, Ahmed et al. ${ }^{15}$ investigated the manufacturing process of two different metal ion $\left(\mathrm{Ti}^{2+}\right.$ and $\left.\mathrm{Fe}^{3+}\right)$ doped phosphate core/clad glass fibres, a process previously limited to manufacturing optical glass fibres only. The manufacturing process of core/clad glass fibres included the following steps: a) preparation of glass billets with varying compositions (but similar thermal transition and viscosity profiles) via casting in a graphite mould, b) co- 
extrusion of the stacked glass billets by placing the cladding glass underneath the core glass to produce the core/clad pre-form (see Figure 3a), and c) the core/clad fibres (Figures 3b) were then drawn from the core/clad pre-form utilising a fibre drawing tower.

a)

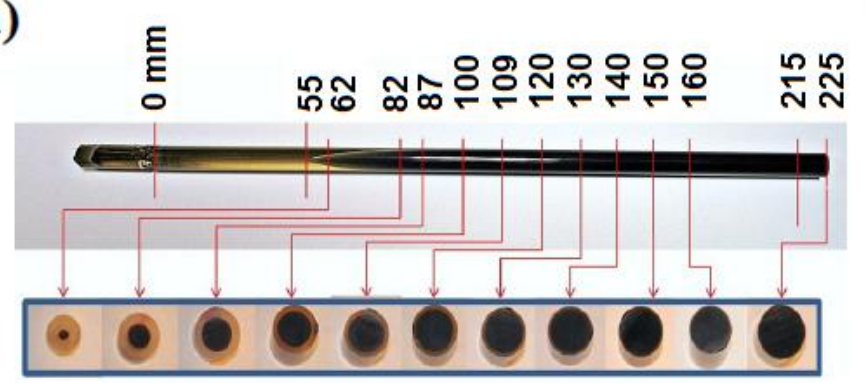

b)

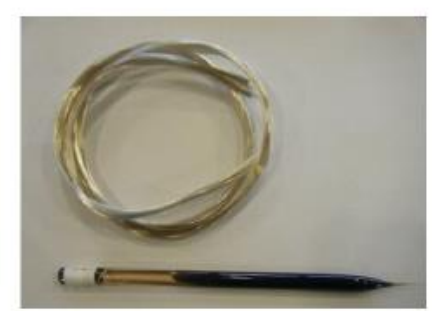

Figure 3: a) Cross-sections of an extruded core/clad preform (the values indicate the cut distance of the preform into discs) and b) an extruded core/clad preform and resultant fibres 15 .

\subsection{Properties of phosphate glass fibres}

Producing fibres from phosphate glass compositions initially proved to be quite challenging, as various parameters such as the melt temperature, melt viscosity, O/P ratio and drawing speed for manufacture of continuous fibres from varying formulations were ascertained mainly through trial and error experimentation. Properties of glass fibres such as, thermal, mechanical, and dissolution properties differ significantly from those of the bulk glass. This variation in properties depends on several factors such as fibre manufacturing methodology, drawing parameters (temperature, speed, viscosity) and fibre diameter. In addition, the properties of PGFs also depend on the bonds present within the molten glass which provide the required strength to withstand the applied stresses during the fibre drawing process. The type of chain forming bonds and the cross-linked networks within the glass structure can be controlled by varying the compositions produced in order to tailor the fibre properties required $^{3}$. 
The main glass forming oxide for phosphate glasses is phosphorus pentoxide $\left(\mathrm{P}_{2} \mathrm{O}_{5}\right)$ which consists of tetrahedral phosphate anions $\left(\mathrm{PO}_{4}^{-3}\right)$. The addition of alkaline and alkaline earth metal ions results in depolymerisation of the phosphate network via creation of a nonbridging oxygen $\left(\mathrm{O}^{-} \mathrm{M}^{+}\right)$by breaking the bridging oxygen ( $\mathrm{P}-\mathrm{O}$ bonds). Moreover, the field strength created via the formation of strong $\mathrm{O}^{-} \mathrm{M}^{+}$bonds due to addition of modifying ions within the glass structure improves their chemical durability ${ }^{16}$. Some metal oxides have high resistance to hydration; for example, addition of $\mathrm{Al}_{2} \mathrm{O}_{3}, \mathrm{Fe}_{2} \mathrm{O}_{3}$ and $\mathrm{TiO}_{2}$ within $\mathrm{PG}$ systems have been shown to significantly decrease the dissolution rates of these glasses ${ }^{17}$. Trivalent ions such as iron $\left(\mathrm{Fe}^{3+}\right)$ and $\left(\mathrm{Ti}^{3+}\right)$ have been found to have a greater influence on the solubility of phosphate glasses than divalent or monovalent ions, which has been suggested to be due to the strengthening of the phosphate network via their cross-linking effect.

Phosphate glass fibres with various compositions, including binary, ternary and quaternary formulations have been investigated for their biocompatibility and degradation profiles ${ }^{5,18}$. Ahmed et al. ${ }^{1,5}$ reported that the degradation rates of phosphate glass fibres (within ternary systems $\mathrm{P}_{2} \mathrm{O}_{5}-\mathrm{CaO}-\mathrm{Na}_{2} \mathrm{O}$ ) increased significantly compared to bulk glass of the same composition. Moreover, the degradation rates for glass fibres increased with decreasing fibre diameter, which was due to the vast increase in surface area compared to the bulk glass. Furthermore, varying the additions of mono, di or trivalent cations (such as $\mathrm{Na}_{2} \mathrm{O}$, $\mathrm{CaO}, \mathrm{MgO}$ or $\mathrm{Fe}_{2} \mathrm{O}_{3}$ etc) within the glass structure enables further control over their degradation rates in aqueous media. For example, addition of $\mathrm{Fe}_{2} \mathrm{O}_{3}$ content (from 1 to 5 mole\%) within the iron phosphate glass system $\left(\mathrm{P}_{2} \mathrm{O}_{5}-\mathrm{CaO}-\mathrm{Na}_{2} \mathrm{O}-\mathrm{Fe}_{2} \mathrm{O}_{3}\right)$ revealed a significant reduction in the glass dissolution rates (dissolution rate $\sim 0.00045$ and $\sim 0.00004$ $\mathrm{mg} . \mathrm{cm}^{-2} \cdot \mathrm{hr}^{-1}$ for the addition of 1 and 5 mol\% $\mathrm{Fe}_{2} \mathrm{O}_{3}$ in the glass system, respectively ${ }^{5}$.

Mechanical properties of glass fibres depend not only on the bonds present within the glass but also their molecular organisation which is related to their chemical composition ${ }^{19,} 20$. The chemical bonds in bulk phosphate glass generally exist as an isotropic structure, however during fibre production the glass network transforms into anisotropic structure and the $\mathrm{PO}_{4}$ tetrahedra align in the direction of the pull ${ }^{21,22}$. The diameter of glass fibres is also known to strongly influence the mechanical properties of glass fibres ${ }^{23}$. For example, Lin et al. ${ }^{24}$ reported that tensile strength and modulus properties of calcium-iron phosphate 
glass fibres increased from $587 \mathrm{MPa}$ to $1045 \mathrm{MPa}$ and $43 \mathrm{GPa}$ to $64 \mathrm{GPa}$, respectively, as the iron content increased from 3.6 to 16.9 mol\%. More recently, Sharmin et al. ${ }^{9}$ reported that addition of 5 and 10 mol\% boron within phosphate glass fibre structures resulted in a significant increase in tensile strength with values of $1050 \mathrm{MPa}$ and $1200 \mathrm{MPa}$ reported, respectively, whilst the control glass fibres without boron exhibited tensile strengths around $530 \mathrm{MPa}$. They also suggested that incorporation of boron had a significant effect on improving the fibre drawing properties (for example, easing fibre formation) which was attributed to the extension of the phosphate chains via boron addition. By simple modification of the glass chemical composition a range of mechanical properties can be achieved (see Table 1).

Table 1: Mechanical properties of phosphate glass fibres

\begin{tabular}{|c|c|c|c|c|}
\hline $\begin{array}{l}\text { Glass composition } \\
\text { (mol\%) }\end{array}$ & $\begin{array}{l}\text { Fibre } \\
\text { diameter } \\
(\mu \mathrm{m})\end{array}$ & $\begin{array}{l}\text { Tensile } \\
\text { strength } \\
\text { (MPa) }\end{array}$ & $\begin{array}{l}\text { Tensile } \\
\text { modulus } \\
\text { (GPa) }\end{array}$ & References \\
\hline $63.7 \mathrm{P}_{2} \mathrm{O}_{5}-32.7 \mathrm{CaO}-3.6 \mathrm{Fe}_{2} \mathrm{O}_{3}$ & $\sim 20$ & 587 & 43 & Lin et al. ${ }^{24}$ \\
\hline $56.9 \mathrm{P}_{2} \mathrm{O}_{5}-26.2 \mathrm{CaO}-16.9 \mathrm{Fe}_{2} \mathrm{O}_{3}$ & $\sim 20$ & 1045 & 64 & Lin et al. ${ }^{24}$ \\
\hline $50 \mathrm{P}_{2} \mathrm{O}_{5}-50 \mathrm{CaO}$ & $20-25$ & 474 & 44 & Ahmed et al. ${ }^{25}$ \\
\hline $50 \mathrm{P}_{2} \mathrm{O}_{5}-40 \mathrm{CaO}-5 \mathrm{Na}_{2} \mathrm{O}-5 \mathrm{Fe}_{2} \mathrm{O}_{3}$ & $20-25$ & 456 & 51.5 & Ahmed et al. ${ }^{6}$ \\
\hline $45 \mathrm{P}_{2} \mathrm{O}_{5}-16 \mathrm{CaO}-15 \mathrm{Na}_{2} \mathrm{O}-24 \mathrm{MgO}-\mathrm{OB}_{2} \mathrm{O}_{3}$ & $\sim 20$ & 530 & 53.4 & Sharmin et al. ${ }^{9}$ \\
\hline $45 \mathrm{P}_{2} \mathrm{O}_{5}-16 \mathrm{CaO}-10 \mathrm{Na}_{2} \mathrm{O}-24 \mathrm{MgO}-5 \mathrm{~B}_{2} \mathrm{O}_{3}$ & $\sim 20$ & 1050 & 59.6 & Sharmin et al. ${ }^{9}$ \\
\hline $45 \mathrm{P}_{2} \mathrm{O}_{5}-16 \mathrm{CaO}-5 \mathrm{Na}_{2} \mathrm{O}-24 \mathrm{MgO}-10 \mathrm{~B}_{2} \mathrm{O}_{3}$ & $\sim 20$ & 1200 & 60 & Sharmin et al. ${ }^{9}$ \\
\hline $45 \mathrm{P}_{2} \mathrm{O}_{5}-16 \mathrm{CaO}-11 \mathrm{Na}_{2} \mathrm{O}-24 \mathrm{MgO}-4 \mathrm{Fe}_{2} \mathrm{O}_{3}$ & $\sim 26$ & 569 & 57 & Liu et al. ${ }^{26}$ \\
\hline $40 \mathrm{P}_{2} \mathrm{O}_{5}-16 \mathrm{CaO}-16 \mathrm{Na}_{2} \mathrm{O}-24 \mathrm{MgO}-4 \mathrm{Fe}_{2} \mathrm{O}_{3}$ & $\sim 15$ & 370 & 62 & Felfel et al. ${ }^{27}$ \\
\hline $40 \mathrm{P}_{2} \mathrm{O}_{5}-16 \mathrm{CaO}-20 \mathrm{Na}_{2} \mathrm{O}-24 \mathrm{MgO}$ & $\sim 15$ & 484 & 44 & $\begin{array}{l}\text { Cozien-Cazuc } \\
\text { et al. }{ }^{28}\end{array}$ \\
\hline
\end{tabular}




\subsection{Biomedical applications of phosphate glass fibres}

As mentioned above, phosphate glasses in the form of fibrous structures containing various modifiers such as iron, zinc, copper, and/or titanium have been explored for a range of biomedical applications. The iron ions released from iron-phosphate glass could potentially participate in redox reactions for certain types of proteins (such as, cytochrome, myoglobin, etc) and could also promote cell attachment and differentiation. For example, Ahmed et al. ${ }^{5}$ investigated the use of iron-phosphate glass fibres as potential cell delivery vehicles for transplantation purposes and used them to orientate muscle precursor cells along the axis of the fibres to form myotubes (see Figure 4). The chemical durability of these glass fibres achieved played a vital role in improving the biocompatibility, and showed that incorporating modifier ions such as iron oxide, the dissolution rates of the glass fibres could be reduced by orders of magnitude. It has been also suggested that iron-phosphate glass fibres containing 4-5 mol\% $\mathrm{Fe}_{2} \mathrm{O}_{3}$ were favourable for cell attachment and differentiation ${ }^{5}$. In addition, iron doped PGFs with diameters ranging between 20-25 $\mu \mathrm{m}$ were suggested to be of suitable size for attachment of human osteoblast and fibroblast cells compared to the 10-15 $\mu \mathrm{m}$ fibres due to their higher surface curvature ${ }^{29}$. Fibres with various diameters differ in their surface curvature; usually fibres with larger diameter possess higher surface curvature which could positively influence cell attachment and spreading.
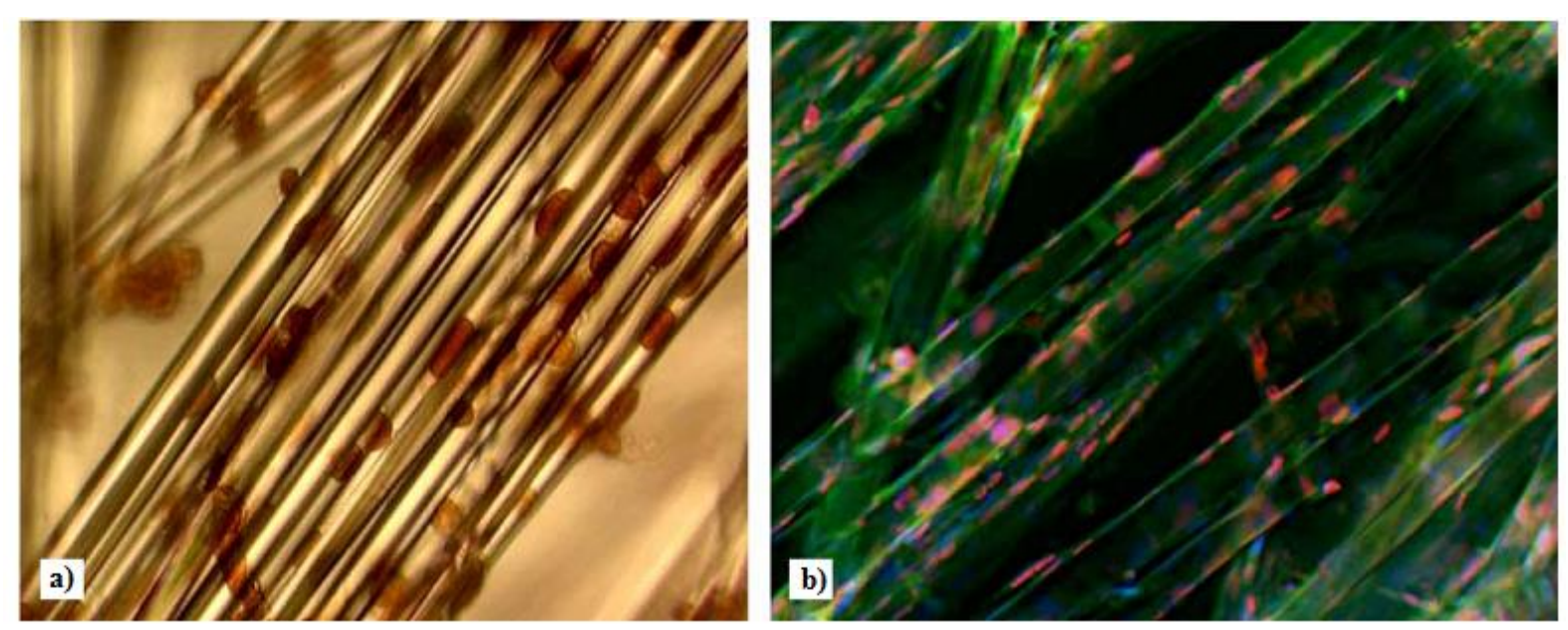

Figure 4: a) Attached muscle precursor cells (MPCs) on iron-phosphate glass fibres and b) MSCs differentiation on PG fibres: Desmin (seen in green) is a cytoplasmic marker of all skeletal muscle cells. Myogenin (seen as Red) is a nuclear marker of differentiation. The Blue 
is DAPI(4,6-diamidino-2-phenylindole (which stains all nuclei)). Adapted with permission from ${ }^{5}$.

Zn ions are well known to stimulate protein synthesis in osteoblast cells and also to increase ATPase and ALP activity ${ }^{30}$. Zinc doped PGFs in the form of 3D-scaffolds were investigated by Shah et al. ${ }^{31}$ for the construction of muscle organoid units. Skeletal muscle cells were found at the interstices of the phosphate fibres and revealed increased cell numbers on the fibre constructs. Ti doped phosphate glass fibres and their role in neuronal polarisation and axonal growth direction have also been investigated by Vitale-Brovarone et al. ${ }^{32}$ who suggested that the aligned configuration of the fibres provided the directional cue for growing Dorsal Root Ganglia (DRG) neurons along the fibre axis (see Figure 5a). Active proliferation of neonatal olfactory bulb ensheathing cells (NOBEC) extending along the PGF surfaces were observed as shown in Figure $5 b$.
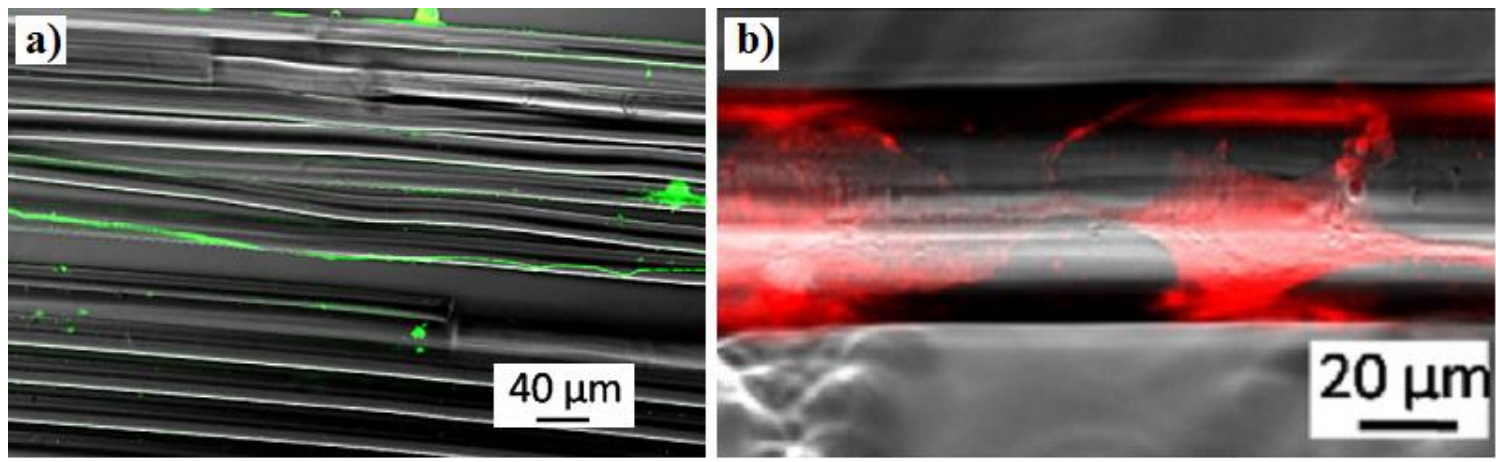

Figure 5: Confocal microscope images of a) DRG neurons on glass fibres presenting long neuritis extended along the fibre axis direction and b) NOBEC cells showing active proliferation on Phosphate glass fibres. Adapted with permission from ${ }^{32}$.

Release of copper ions from PGFs was investigated by Abou Neel et al. ${ }^{33}$ for their potential antibacterial properties against Staphylococci. It has been suggested that incorporation of $10 \mathrm{~mol} \% \mathrm{CuO}$ released sufficient $\mathrm{Cu}^{2+}$ ions as the glass degraded to prevent bacterial colonisation and reduce the number of viable bacteria in the local environment. Copper ions have also been reported to have other advantages such as, stimulation of angiogenesis and also proliferation of human endothelial cells. As such, $\mathrm{Cu}$-doped glasses could also potentially be used for wound healing applications ${ }^{34}$. 


\section{Phosphate glass fibre-reinforced composites:}

The principal limitation for widespread use of bioresorbable polymers for biomedical applications are usually due to their mechanical properties, although the mechanical characteristics for some bioresorbable polymers are known to be sufficient for non-load bearing applications such as the cranial (skull) bones and maxillofacial fractures. Fractures at load bearing sites (e.g. femur and tibia) require sufficiently robust fixation devices to avoid implant failure until the fractured bone has healed. Therefore, reinforcement of these polymers has been considered to produce composite implants with enhanced mechanical properties to match cortical bone. In order to produce fully bioresorbable implants, the reinforcement phase should also be made from biocompatible and bioresorbable materials. These composite devices could also eliminate potential inflammatory responses associated with the use of resorbable polymers alone, which has mainly been ascribed to the acidic degradation products from these polymers (such as lactic acid for PLA) ${ }^{35-37}$. These acidic breakdown products could potentially be buffered via the degradation by-products from the reinforcement phase. The $\mathrm{pH}$ of the media during glass degradation is important for composite stability and degrading glass compositions which cause an acidic $\mathrm{pH}$ may not be ideal for biomedical applications. However, controlling $\mathrm{pH}$ during degradation of PGs is just a matter of altering their composition. This was demonstrated by Ahmed et al. ${ }^{9}$, who showed that PGs could maintain a neutral pH level which would assist in buffering the polymer degradation by-products (see Figure 6) Moreover, the amount of polymer matrix within the composite would decrease at the expense of the reinforcement leading to less polymer remaining to be eliminated.

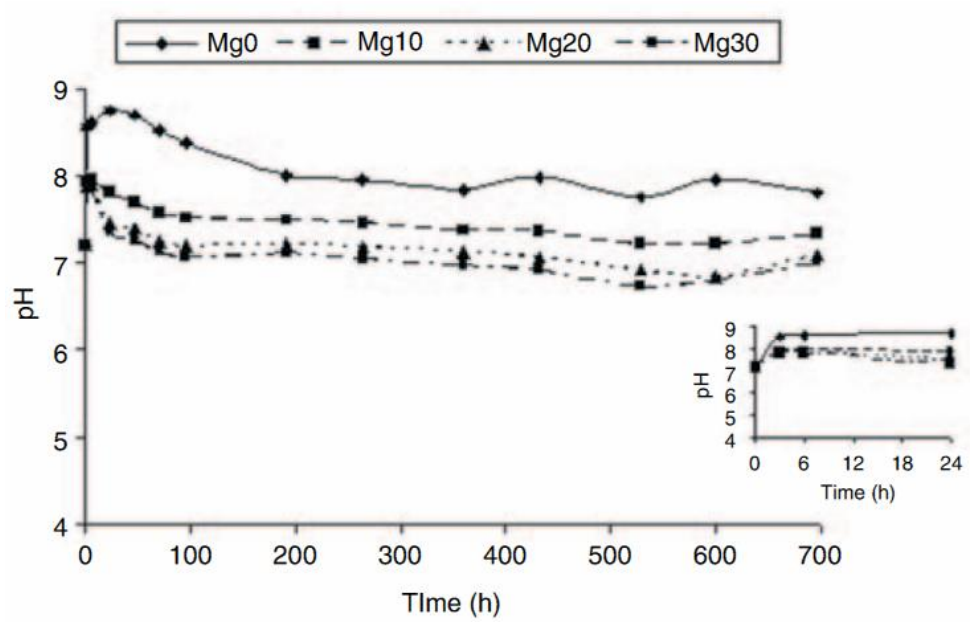


Figure 6: $\mathrm{pH}$ values obtained for $40 \mathrm{P}_{2} \mathrm{O}_{5}-25 \mathrm{CaO}-(35-\mathrm{x}) \mathrm{Na}_{2} \mathrm{O}-\mathrm{xMgO}$ glasses, $\mathrm{x}$ varied from 0 to 30 mol\%. $\mathrm{pH}$ remained relatively neutral over time ${ }^{9}$.

Composites are generally comprised of a stiff and strong dispersed phase (reinforcement) and continuous phase (matrix). Properties of the composites depend on properties of the constituents as well as the geometry, size, distribution and volume fraction of the reinforcement phase. Furthermore, the bonding strength (adhesion) between the phases plays a crucial role in their properties. Increase in reinforcement (fibres/matrix bonding) allows for effective load transfer leading to higher strength profiles for the composite ${ }^{38}$.

Biocomposites are composite materials that can be implanted inside the body to replace the function of living tissue ${ }^{39}$. They may be grouped into fully, partial and non bioresorbable composites based on the ability of the constituents to degrade and resorb within the body 40. The matrix and reinforcement have to be bioresorbable for a fully bioresorbable composite (e.g. PCL/PGF, PLA/PGF ${ }^{25}{ }^{41}$ ), whilst both can be biostable for non-resorbable composites (for e.g. ultra-high molecular weight polyethylene/hydroxyapatite (UHMWPE/HA) ${ }^{42}$ ). For partial bioresorbable composites, one of the composite components (usually the reinforcement) is biostable (e.g. PLA/bioglass, PLA/carbon fibre ${ }^{43-45}$ ).

Fibre reinforced composites (FRC) could potentially provide a wide range of mechanical properties to match both cortical and cancellous bone ${ }^{46,47}$. For instance, the anisotropic nature of the bone (i.e. the longitudinal mechanical properties of bone are greater than the transverse direction) can be achieved by continuous unidirectional fibre reinforced composites ${ }^{46}$. The orientation of fibres could be aligned or be present in a random format (as in chopped strand fibre mats) to influence the mechanical performance of the composites produced ${ }^{48,49}$. Properties of fibre reinforced composites are controlled by fibre volume fraction, type, length, distribution and strength of fibre/matrix interface 46,47 . Various types of fibres have been utilised in the orthopaedic field such as carbon ${ }^{50}$, bioglass 45, 51-56 and phosphate glass fibres ${ }^{25,41,57-63}$.

Aspect ratio (length to diameter ratio) of the fillers also has a significant influence on the modulus/stiffness of a particulate composite ${ }^{64,65}$. Mechanical properties of composites are known to increase as the aspect ratio of the particles increases. Therefore, it is expected 
that the reinforcing efficiency of fibres is significantly greater than particles. The parameters which affect the mechanical behaviour of FRCs are summarised in Figure 7 below.

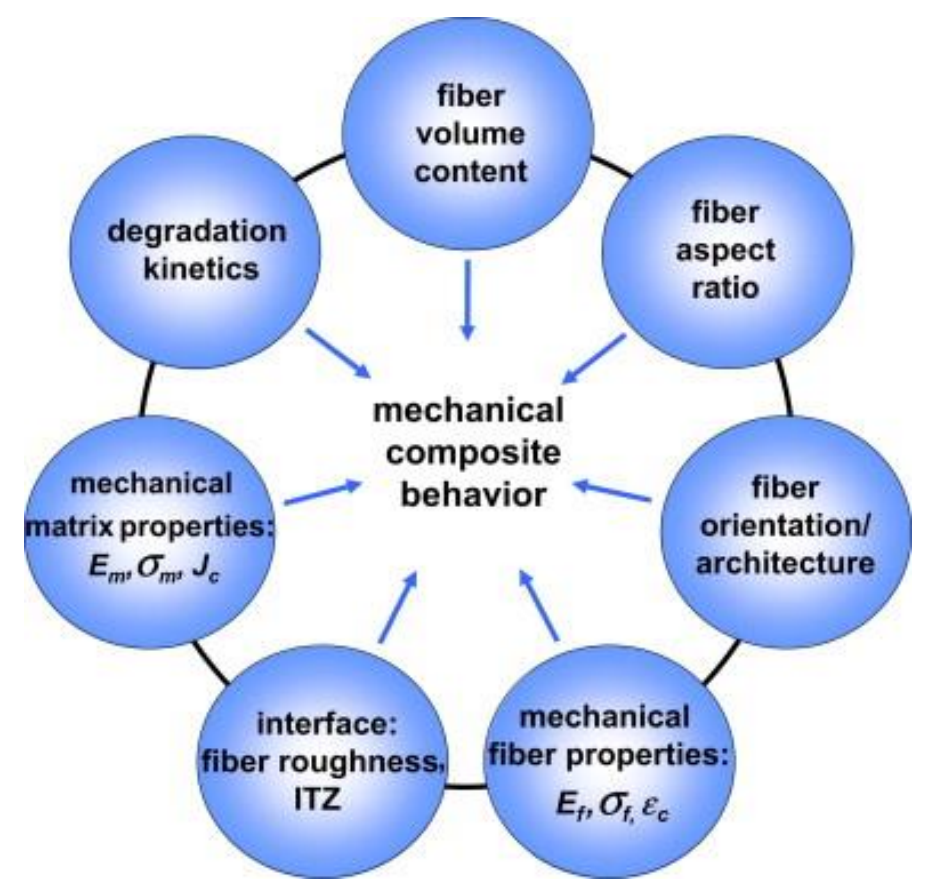

Figure 7: Schematic diagram of parameters which control the mechanical properties of fibre reinforced composites. Adapted with permission from ${ }^{66}$.

Bioresorbable fibres such as phosphate glass fibres (PGF) have been investigated to manufacture fully bioresorbable composites due to their unique resorption profiles. Composite plates based on PLA and PGF have been produced with different fibre content and lay-up geometries. Flexural properties for unidirectional composites with fibre volume fraction $\left(\mathrm{V}_{\mathrm{f}}\right) \sim 30 \%$ and $\sim 55 \%$ of $115 \mathrm{MPa}$ and $170 \mathrm{MPa}$ for strength and $16 \mathrm{GPa}$ and $15 \mathrm{GPa}$ for modulus respectively, have been achieved 57, 58. Furthermore, PLA reinforced with random PGF mats $\left(V_{f} \sim 14 \%\right)$ achieved properties of $90 \mathrm{MPa}$ and $5 \mathrm{GPa}$ for bending strength and modulus respectively ${ }^{41}$.

\subsection{Manufacturing PGF composites}

\subsubsection{Compression moulding}


Random mat (RM) and unidirectional (UD) composites have been prepared via a laminate film stacking process. PLA or PCL films were stacked alternately with RM or UD aligned fibres (see Figure 8) in a mould cavity between two metallic plates. The stack was then heated in the press for 15 mins above melting temperature of the polymer matrix $\left(210\right.$ and $120^{\circ} \mathrm{C}$ for PLA and PCL respectively) and pressed for 15 mins at 38 bar. The plates were transferred to a second press for cooling to room temperature at 38 bar for 15 mins ${ }^{25,67}$.

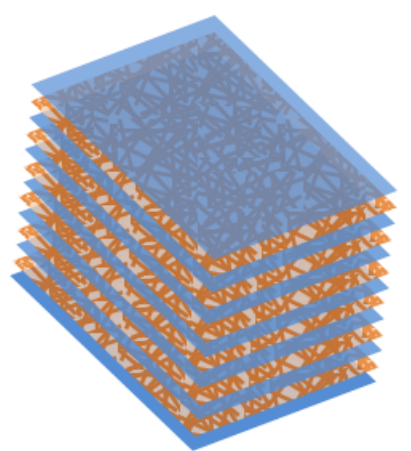

(a)

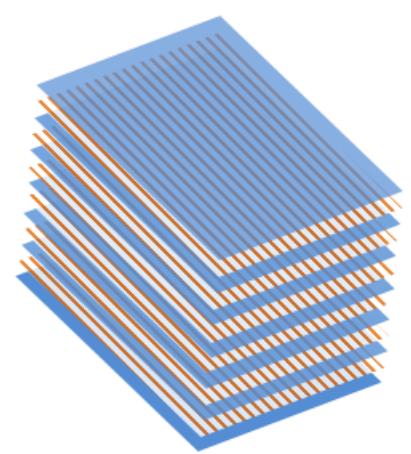

(b)

Figure 8: Schematic diagram for film stacking process for producing; (a) RM and (b) UD composites.

\subsubsection{In situ polymerisation}

PCL based composites have also been prepared via an in situ polymerisation process. The catalyst, $\mathrm{Sn}(\mathrm{Oct})_{2}$, was mixed with $\varepsilon$-caprolactone at the molar ratio of $1 / 1000$ and then injected into a dried polytetrafluoroethylene (PTFE) mould (see Figure 9) at room temperature. The amount of unidirectional PGF was determined based on the target fibre volume fraction of the composites and placed in the mould before injection of reaction mixture. Parts of the mould were carefully sealed and then kept at $110^{\circ} \mathrm{C}$ for 24 hours to complete the polymerisation reaction. ${ }^{45}$. 


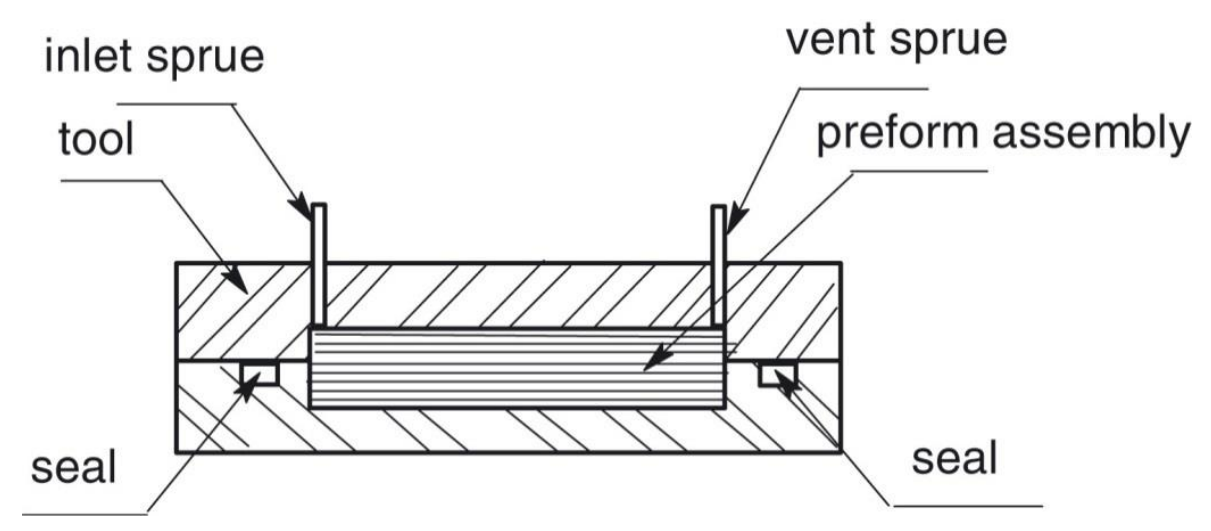

Figure 9: A schematic diagram for in situ polymerisation process that used in preparation of PCL-PGF composites. Adapted with permission from ${ }^{45}$.

\subsection{Properties of PGF based composites:}

The flexural properties of PGF reinforced composites investigated over recent years have been summarised in Figures 10 \& 11. Flexural strength and modulus for both RM and UD composites increased as the fibre volume fraction $\left(V_{f}\right)$ increased especially for the $40 \%$ and $45 \% V_{f} R M$ and UD composites as expected. The range of values obtained spanned between 15 to $370 \mathrm{MPa}$ for strength and between 1 and $25 \mathrm{GPa}$ for modulus (well exceeding the mechanical properties of human bone, which ranges between 45 to $270 \mathrm{MPa}$ and 5 to 23 GPa for strength and modulus respectively). When the fibre content increased $35 \%$, the strength and modulus for the composites remained approximately constant or decreased slightly due to breaking of fibres and lack of fibre impregnation within the polymer matrix. UD composites showed significantly higher flexural properties compared to RM composites as expected based on the rule of mixtures and due to high efficiency of aligned fibres to transfer stress across the fibre matrix interface in comparison with random chopped fibres. Sizing the fibres with coupling agents caused a significant increase in flexural properties for RM and UD composites. This was attributed to enhancement of fibre-matrix interface. As seen from Figure 11, the flexural properties of UD composites containing more than $15 \%$ fibre volume fraction surpassed the lower limits of cortical bone mechanical properties. The huge variation of flexural properties for composites at constant fibre volume fraction is ascribed to differences in mechanical properties of the PGFs used (with varying compositions), as highlighted in Table 1. 


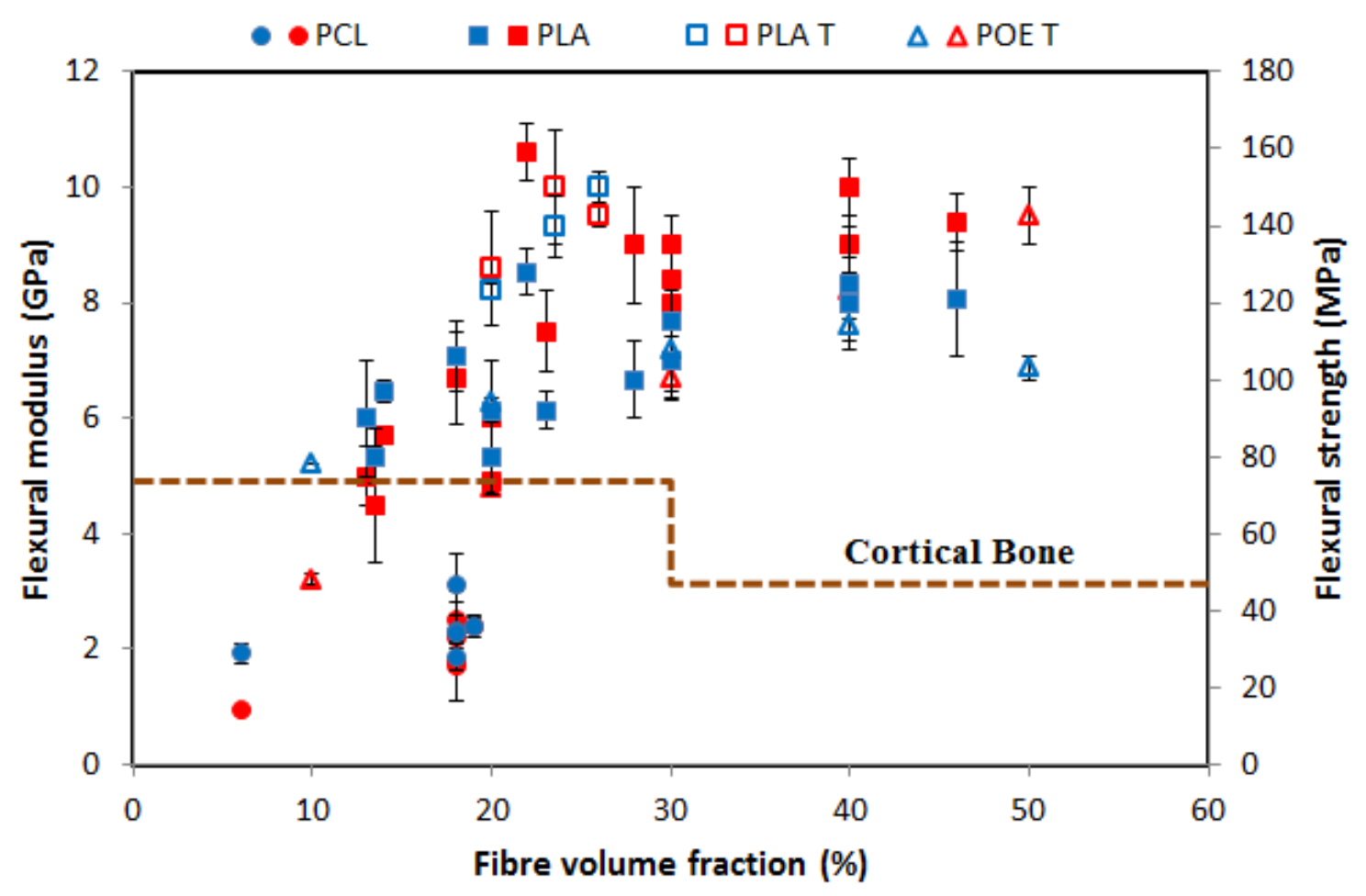

Figure 10: Flexural properties of compression moulded PGF RM composites against fibre volume fraction. Symbols in blue and red represents flexural strength and modulus respectively and unfilled symbols refer to composites containing treated PGF with coupling agents. PCL: polycaprolactone, PLA: poly lactic acid, POE: poly(ortho ester) and T refers to treated fibres with coupling agent ${ }^{41,61,68-72}$. 


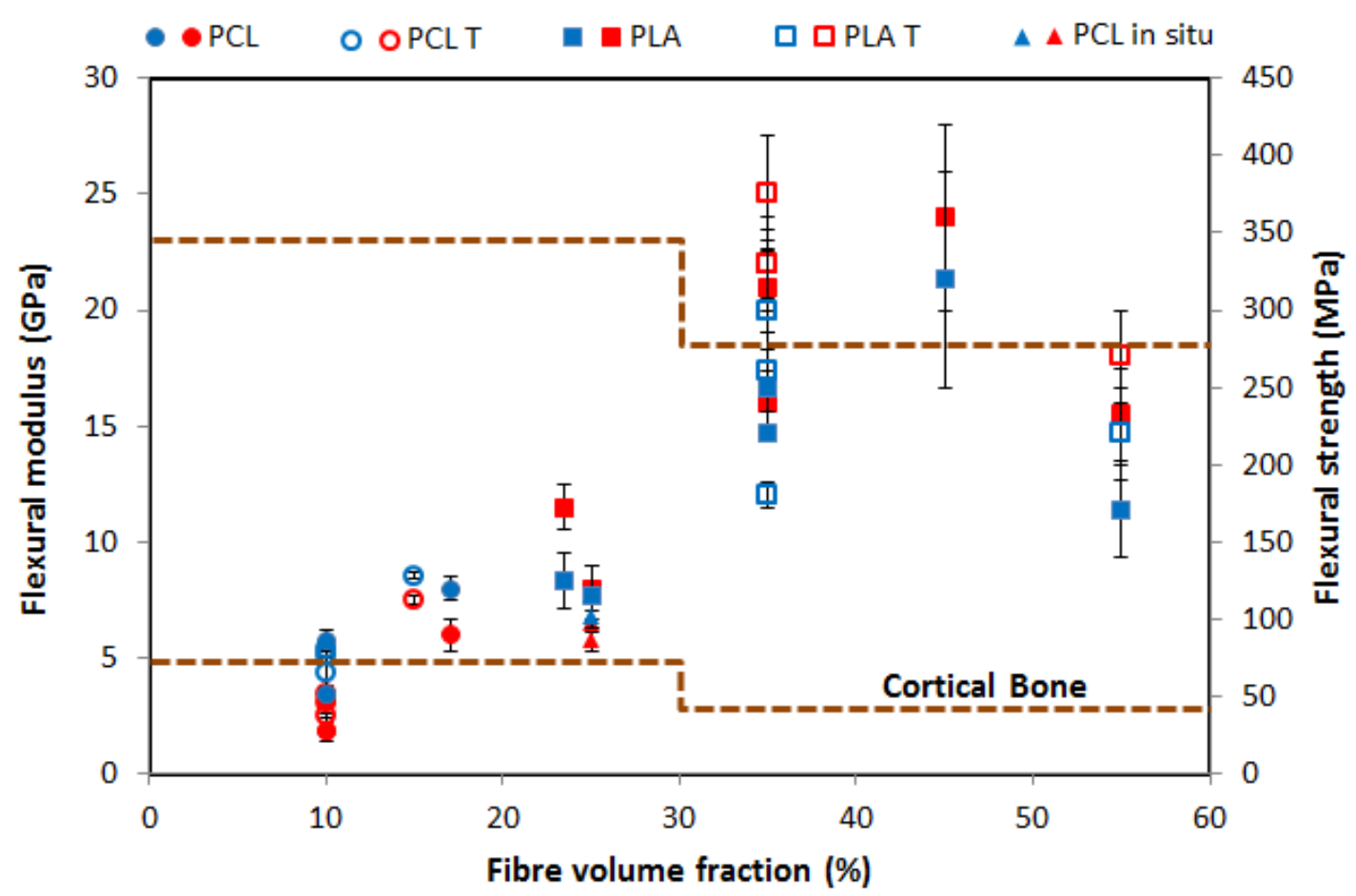

Figure 11: Flexural modulus and strength of PLA and PCL reinforced with UD PGF versus fibre volume fraction. Symbols in blue and red represents flexural strength and modulus respectively and unfilled symbols refer to composites containing treated PGF with coupling agents. PCL: polycaprolactone, PLA: poly lactic acid and $T$ refers to treated fibres with coupling agent $58,61,71,73-77$.

Ahmed et al. ${ }^{41}$ produced PLA-PGF composites containing 14\% fibre volume fraction with initial flexural properties of $90 \mathrm{MPa}$ for strength and $5 \mathrm{GPa}$ for modulus. The values decreased to $40 \mathrm{MPa}$ and $1 \mathrm{GPa}$ respectively after immersion in deionised water at $37^{\circ} \mathrm{C}$ for 6 weeks. Further studies by Ahmed et al. 61 investigated degradation and mechanical retention for PLA-PGF composites with a range of fibre volume fractions (from $20 \%$ to $45 \%$ ) and fibre orientations. The initial flexural strength and modulus for RM composites increased to $\sim 120 \mathrm{MPa}$ and $\sim 10 \mathrm{GPa}$ with increasing fibre volume fraction to $\sim 45 \%$. Flexural properties for UD composites were $130 \mathrm{MPa}$ for strength and $\sim 11.5 \mathrm{GPa}$ for modulus for $24 \%$ fibre volume fraction composites. These composite mechanical properties decreased by $\sim 50$ and $80 \%$ of their initial strength and modulus after 14 days immersion in deionised water at $37^{\circ} \mathrm{C}$ which was attributed to degradation of the fibre/matrix interface and the PGF fibres. The overall mass loss for the composites also increased with increasing 
fibre volume fraction. Most of the studies investigating particulate and fibre-reinforced composites based on PG have reported a rapid loss of mechanical properties when exposed to media.

Annealed and non-annealed binary calcium phosphate $\left(50 \mathrm{P}_{2} \mathrm{O}_{5}-50 \mathrm{CaO}\right)$ glass fibres have also been used to reinforce PCL. The composites contained two different volume fractions of non-woven random mat fibres, 6.4 and $17 \%$, and revealed flexural modulus and strength of up to $2.5 \mathrm{GPa}$ and $30 \mathrm{MPa}$, which were in the range of human cancellous bone. A good correlation between degradation and ion release profiles was also observed which also revealed a porous structure within the PCL matrix at the end of the degradation period of 5 weeks as a result of the glass fibres resorbing leaving behind continuous channels ${ }^{25}$.

Borbely et al. ${ }^{63}$ explored the degradation and ion release profiles of PCL-PGF composites over 7 days at $37^{\circ} \mathrm{C}$. The weight of all composites initially increased followed by loss in both distilled water and Hanks Buffered Saline Solution (HBSS). The change in weight was the result of water uptake and mass loss due to hydrolytic degradation over time. Initially, water uptake was the dominant factor over weight loss as a result of the hydrophilic nature of PG. However, the weight loss at the end of the study in water was higher than that in HBSS as a result of the buffering effect of HBSS. The SEM micrographs of the composites showed a distinct precipitation of calcium phosphate on their surfaces and the authors reported that these composites could potentially be used as bioactive root fillings.

Mohammadi et al. ${ }^{78}$ prepared PCL-PGF random mat composites with $18 \%$ fibre volume fraction via compression moulding using two formulations of PGF; $50 \mathrm{P}_{2} \mathrm{O}_{5}-40 \mathrm{CaO}-10 \mathrm{Fe}_{2} \mathrm{O}_{3}$ $\left(\mathrm{Fe}_{10}\right)$ and $50 \mathrm{P}_{2} \mathrm{O}_{5}-40 \mathrm{CaO}-5 \mathrm{Fe}-5 \mathrm{SiO}_{2}$ ( $\left.\mathrm{Fe}_{5} \mathrm{Si}_{5}\right)$. PCL- $\mathrm{Fe}_{5} \mathrm{~S}_{i_{5}}$ showed approximately $55 \%$ decrease in flexural strength and modulus after 28 days of degradation at $37^{\circ} \mathrm{C}$, whilst no statistically significant change was seen in flexural strength and modulus for PCL-Fe 10 composites at 7 and 28 days. They also investigated the change in storage modulus for PCLPGF composites over the temperature range from -90 to $37^{\circ} \mathrm{C}$ which increased from 3.7 to 4.5 and 5.5 GPa by incorporation of $\mathrm{Fe}_{10}$ and $\mathrm{Fe}_{5} \mathrm{~S}_{i 5}$ fibres into the PCL matrix. PCL-Fe ${ }_{5} \mathrm{Si}_{5}$ samples revealed greater weight loss and ion release in comparison to $\mathrm{PCL}-\mathrm{Fe}_{10}$ and neat $\mathrm{PCL}$. They also reported that the PCL-Fe ${ }_{5} \mathrm{Si}_{5}$ composites initiated the formation of brushite precipitates on their surface after 14 and 28 days of conditioning in simulated body fluid 
(SBF) at $37^{\circ} \mathrm{C}$. In contrast, no precipitates were observed on the surfaces of PCL-Fe10 and $\mathrm{PCL}$ alone till the 28 day interval.

Rates of degradation and ion release of PLA and PCL composites reinforced with PGF can mainly be controlled by the dissolution rates of the glass formulations used. Moreover, a good correlation has been observed between mass loss and ion release profiles ${ }^{25,79}$. Felfel et al. ${ }^{80,81}$ investigated the effect of chemical formulation of PGF on degradation rate of PLA composites. Two glass formulations $\left(50 \mathrm{P}_{2} \mathrm{O}_{5}-40 \mathrm{CaO}-5 \mathrm{Na}_{2} \mathrm{O}-5 \mathrm{Fe}_{2} \mathrm{O}_{3}\right.$ in mol\% - denoted as $\mathrm{P} 50)$ and $\left(40 \mathrm{P}_{2} \mathrm{O}_{5}-24 \mathrm{MgO}-16 \mathrm{CaO}-16 \mathrm{Na}_{2} \mathrm{O}-4 \mathrm{Fe}_{2} \mathrm{O}_{3}\right.$ in mol\% - denoted as $\left.\mathrm{P} 40\right)$ were used in this study. They found that P50 composites lost 16\% of their weight after 9 weeks of degradation at $37^{\circ} \mathrm{C}$, whilst $\mathrm{P} 40$ composites lost approximately $1 \%$ during the same period. Rates of cations and anions released from the P50 composites were also significantly greater than for the P40 composites due to higher chemical durability of the P40 formulation. Lower phosphate content and shorter chains, excess of Q1 structure and existence of divalent cations, capable of crosslinking phosphate chains, were the main reasons suggested for the enhanced chemical durability of the P40 fibres. Scanning electron micrographs (see Figure 12) of the composites throughout the degradation period revealed that P50 fibres had almost fully degraded and left behind porous PLA structure and P40 fibres remained intact. 

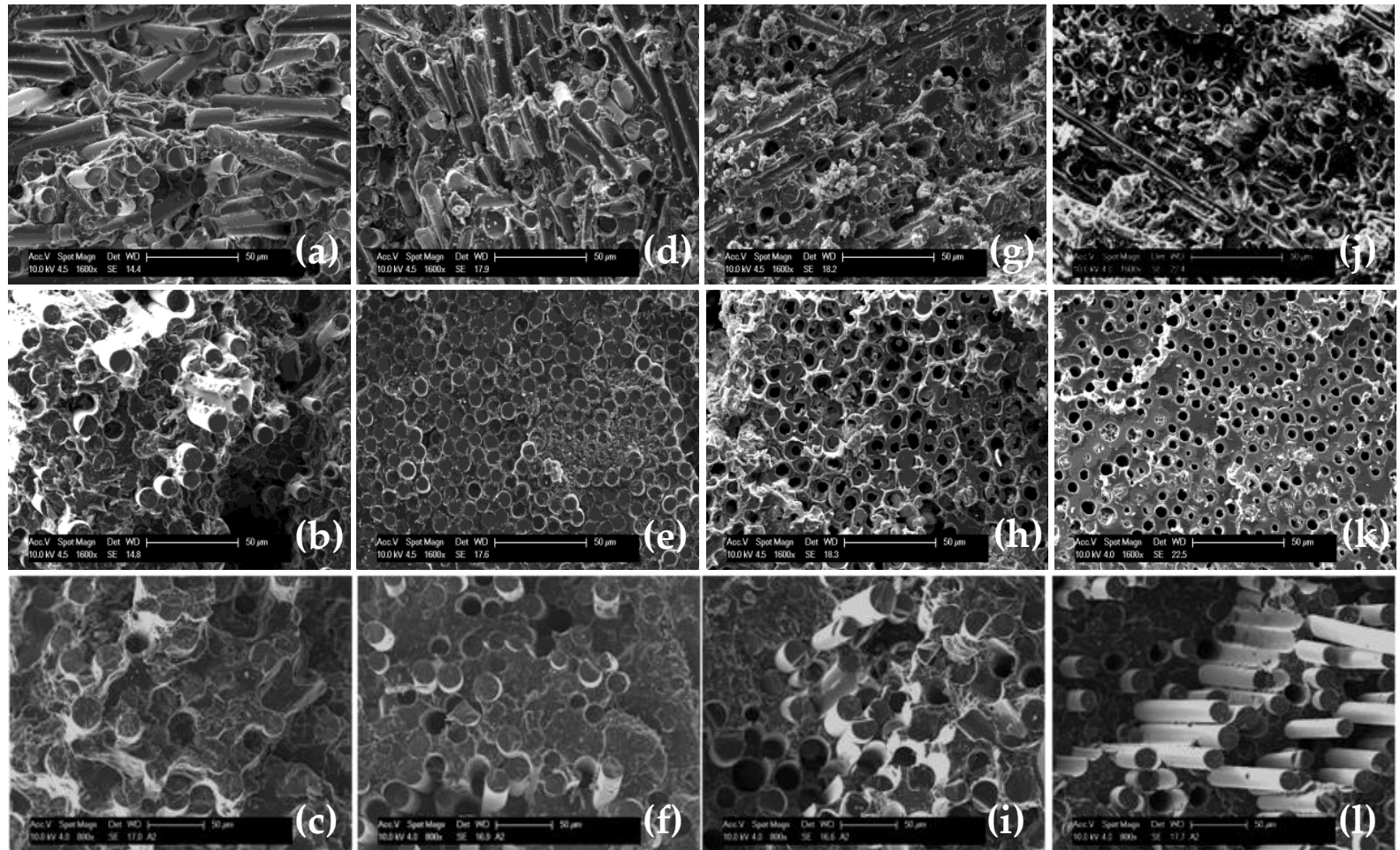

Figure 12: SEM micrographs of a freeze fractured surface for P5O RM, P5O UD and P4O UD composite rods (a), (b) and (c) before degradation, (d), (e) and (f) after 2 weeks of degradation in $\mathrm{PBS}$ at $37^{\circ} \mathrm{C},(\mathrm{g}),(\mathrm{h})$ and (i) after 4 weeks of degradation in $\mathrm{PBS}$ at $37^{\circ} \mathrm{C}$, and (j), (k) and (I) after 9 weeks of degradation in PBS at $37^{\circ} \mathrm{C}$. P4O fibres remained intact after 9 weeks of degradation, while P50 fibres had degraded and left behind porous PLA structure. Scale bars for all micrographs represent $50 \mu \mathrm{m}$. Adapted with permission from ${ }^{80,81}$.

\subsubsection{The fibre/matrix interface}

PGF based composites commonly lose substantial percentage of their initial mechanical properties after immersion in aqueous media due to loss of interfacial integrity. Several studies have thus investigated improving the bonding between PGF and biodegradable polymer matrices such as PCL and PLA using coupling agents $8,68,73-76,82$. In the absence of coupling agents, the fibre/matrix interface is mainly attributed to mechanical adhesion. Treatment of the fibres with coupling agents could potentially introduce chemical bonding with the polymer matrix. 
Hasan et al. ${ }^{68,73,83}$ used varying chemical agents to investigate the fibre/matrix interface in order to enhance mechanical property retention of the composites. They trialed 3phosphonopropionic acid (PPA), glycerol 2-phosphate disodium salt (GP), etidronic acid (EA), 3-aminopropyltriethoxy silane (APS), sorbitol/sodium ended PLA-oligomers (S/Na-PLA), hexamethylene diisocyanate (HDI) and amino phosphonic acid (APA). Covalent bonding was detected between phosphate glass and APS, EA and HDI using IR spectroscopy, whilst GP, PPA, S/Na-PLA and APA were suggested to be linked via hydrogen bonds. Interfacial shear strength (IFSS) values of between 7 to $22 \mathrm{MPa}$ were achieved, after treatment of glasses with APS, EA, HDI and S/Na-PLA, whereas other agents showed little increase in IFSS after immersion in aqueous media. Initial flexural strength of PLA composites reinforced with RM and UD PGF treated with APS exhibited $15 \%$ and $30 \%$ increase respectively compared with composites containing non-treated fibres. However, their strength profiles decreased gradually to be similar to the control composites after one week immersion in PBS at $37^{\circ} \mathrm{C}$. Cytocompatibility of the composites containing treated fibres with different coupling agents was examined using primary human osteoblasts over 21 days. All composites exhibited comparable cytocompatibility to the tissue culture plastic control. Haque et al. ${ }^{8,82}$ also found that the IFSS for PGF treated with Na-PLA and GP increased from 9.5 MPa (for noncoated fibres) to 14.4 and 17.5 MPa respectively. However, the effects of these sizing agents also decreased after 3 days of immersion in PBS at $37^{\circ} \mathrm{C}$ to level with the IFSS values of the non-coated single fibre composites.

Onal et al. ${ }^{84}$ also investigated degradation mechanisms of PGF reinforced PCL composites fabricated using in situ polymerisation method. PGF fibres were treated with a coupling agent (3-aminopropyltriethoxysilane) and the percentage moisture content was observed to increase from 0.38 to $2.42 \%$ as the fibre volume fraction within the composites increased from 0 to $20 \%$. The moisture diffusion coefficient also increased by $40 \%$ with inclusion of 20 $\%$ fibre content.

Liu et al. ${ }^{85}$ investigated coating PGFs with magnesium (Mg) using physical vapour deposition (PVD) in order to enhance adhesion between PGF and PCL and consequently control degradation and mechanical retention properties of the composites. Magnesium coating yielded roughened fibre surfaces (see Figure 13) which could potentially induce a mechanical interlock between the fibres and polymer matrix. Tensile properties of the 
coated fibres decreased initially after coating with magnesium which was suggested to be due to surface damage due to bombardment of $\mathrm{Mg}$ particles during the coating process. The IFSS of PCL-PGF interface increased from 5.2 to $8.9 \mathrm{MPa}$ as the thickness of magnesium coating increased to $4 \mu \mathrm{m}$. However, the IFSS then decreased to similar levels as the noncoated counterparts, when the Mg-coating was $9.5 \mu \mathrm{m}$. Mg-coated PCL-PGF random mat composites showed significantly lower water uptake, mass loss and rate of ion release compared to the non-coated fibre reinforced composites (control group). The tensile strength and modulus of these Mg-coated fibre composites were 17 and $47 \%$ higher than the control (non-coated fibre) composites. In addition, the coated fibre composites retained higher tensile and flexural properties than control composites after 10 days of degradation in PBS at $37^{\circ} \mathrm{C}$. Both coated and non-coated composites revealed good cytocompatibility and no significant difference were observed. Similar findings were obtained for Mg-coated unidirectional (UD) composites. Initial tensile properties for UD composites increased more than $50 \%$ as a result of $\mathrm{Mg}$-coating. They concluded that the $\mathrm{Mg}$-coating inhibited fibre degradation and enhanced the fibre/matrix adhesion, which led to the improvement in mechanical retention and degradation properties achieved.
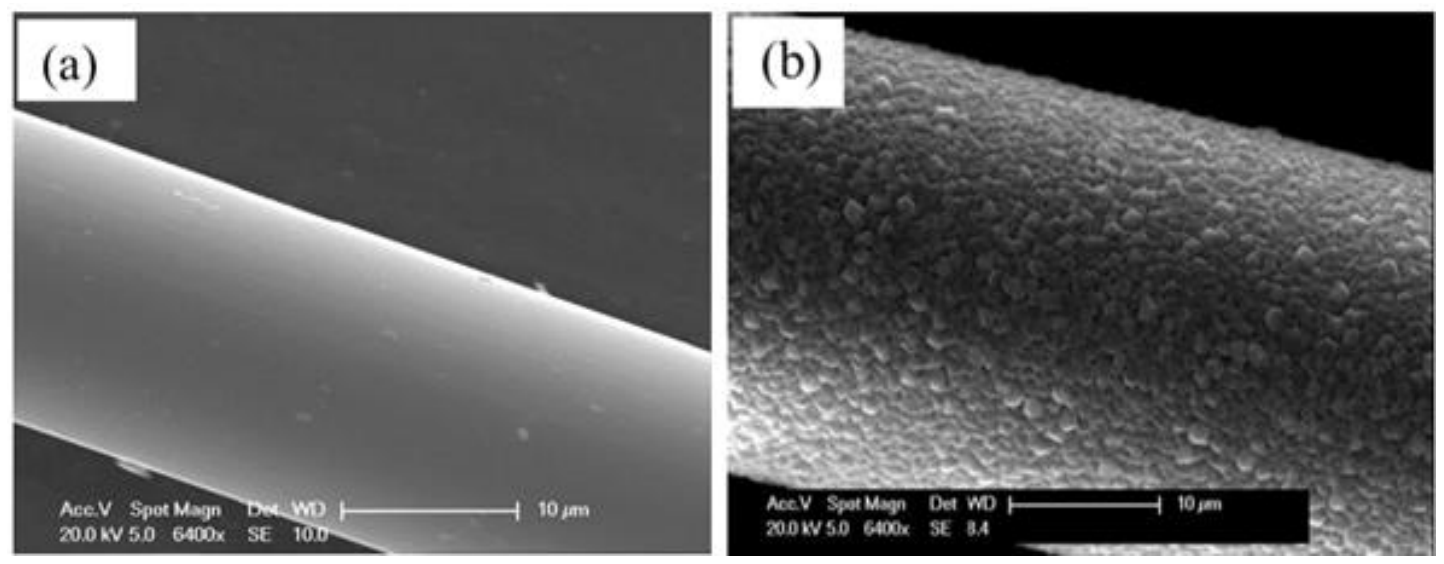

Figure 13: SEM of (a) non-coated and (b) coated PGF with magnesium using PVD. Adapted with permission from ${ }^{85}$. 


\subsection{Biomedical applications of PGF composites}

\subsubsection{Bone repair}

Han et al. ${ }^{86}$ manufactured resorbable PLA-PGF composite plates and demonstrated the effects of drilled screw holes on their mechanical and degradation properties (See Figure 14). Flexural strength and modulus of the UD composites increased gradually from $\sim 200$ to $320 \mathrm{MPa}$ and from 10GPa to 23GPa as the fibre volume fraction increased from 25 to $45 \%$. Moreover, use of a larger number of thin UD layers for the same fibre fraction had a positive effect on mechanical properties for the composites. For instance, composite containing 8 UD thin fibre layers revealed $60 \%$ higher flexural properties than the composite composed of one thick layer of UD fibres. This was attributed to the use of multiple, thinner UD mats providing better fibre wet-out, impregnation and dispersion across the composite thickness which led to stronger fibre/matrix interface resulting in enhanced stress transfer. Drilling screw holes into composite plates revealed a decrease in flexural strength by $6-20 \%$ in comparison with composite plates without holes. Interestingly, they also found that gamma sterilisation had no significant influence on the flexural properties of PLA-PGF composite plates with and without screw holes, which was ascribed to stability of the glass fibres against gamma radiation and that the fibres were the dominating factor in the properties of the composites. Drilling screw holes into laminate composites caused different types of damage such as delamination, cracking, debonding, fibre tearing and polymer softening and deformation around the screw hole. It was also found that the damage was more substantial for UD composites than the RM counterparts. Consequently, use of RM layers at the top and bottom of UD composites revealed a significant decrease in screw-hole damage. Weight loss profiles for both PLA-PGF UD and RM composites increased initially at day 3 followed by a gradual decrease which was ascribed to water uptake. Furthermore, composites containing $45 \%$ fibre volume fraction showed significantly higher mass loss compared to other RM and UD composites. Composite plates with screw holes exhibited slightly faster degradation compared to plates without holes due to increase in the surface $\operatorname{area}^{86}$. 

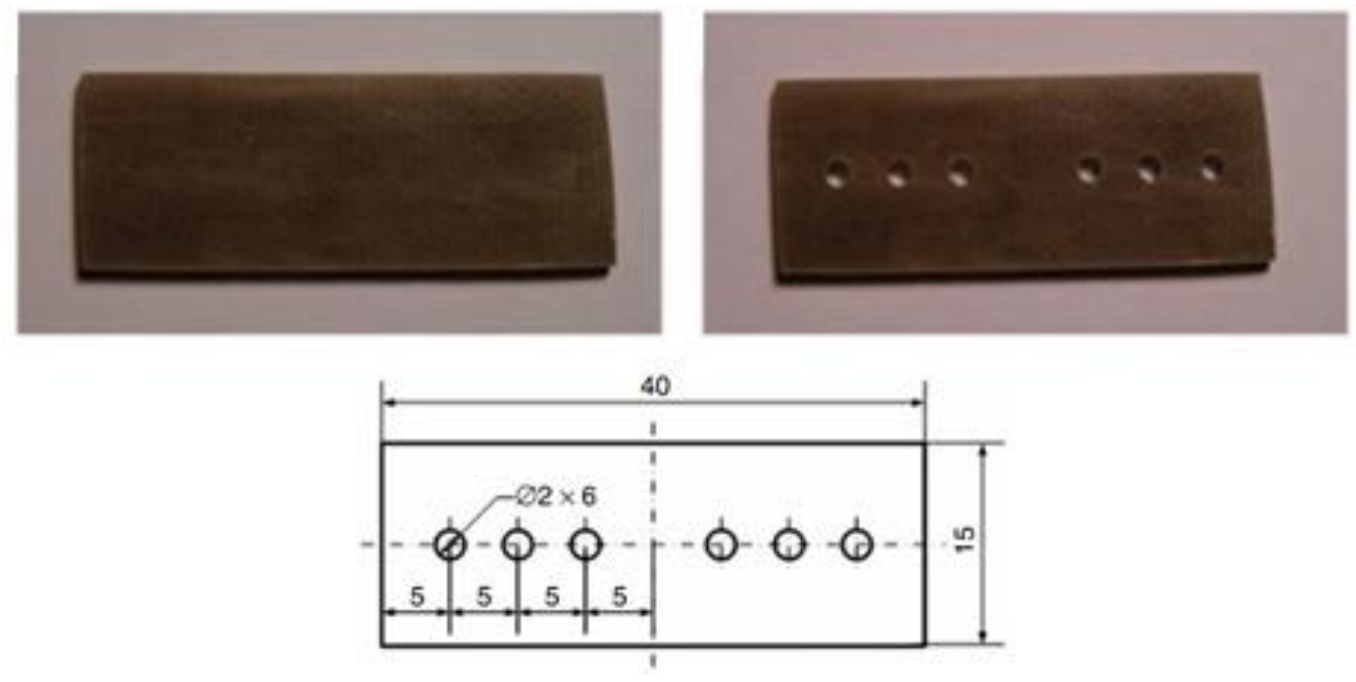

Figure 14: PLA-PGF Composite plates before and after drilling screw holes. Screw holes have $2 \mathrm{~mm}$ diameter and span between holes is $5 \mathrm{~mm}$. Adapted with permission from ${ }^{86}$.

A novel method introduced by Felfel et al. ${ }^{79,87-90}$ for reshaping PLA-PGF composite plates into rods and screws (i.e. via forging or thermomechanical deformation) was applied during their rubbery state (i.e. above $T_{g}$ of PLA) and below the crystallisation temperature $\left(T_{c}\right)$ in order to prevent an increase in matrix crystallinity which could lower the degradation rate of the implant ${ }^{91-93}$. The forging process window was selected between $70-90^{\circ} \mathrm{C}$ and this technique had numerous advantages; low processing temperatures, low cost, small void ratio, appropriate for different designs, shapes and materials, exclusion of aggressive thermal degradation and improvement of the matrix mechanical properties. The composite plates were forged at $\sim 90^{\circ} \mathrm{C}$ into rods and screws. The forging technique improved the mechanical properties which were attributed to both the orientation of polymer chains in the matrix and the short chopped random mat fibres rearranging along the principal axis of the rods. PLA-PGF rods and screws showed comparable initial mechanical properties to cortical bone. Initial flexural, shear and compressive strengths of the rods varied within ranges of $100-250 \mathrm{MPa}, 60$ - $90 \mathrm{MPa}, 130-420 \mathrm{MPa}$ respectively and the flexural modulus ranged from 7 to $25 \mathrm{GPa}$ depending on fibre volume fraction and architecture. 

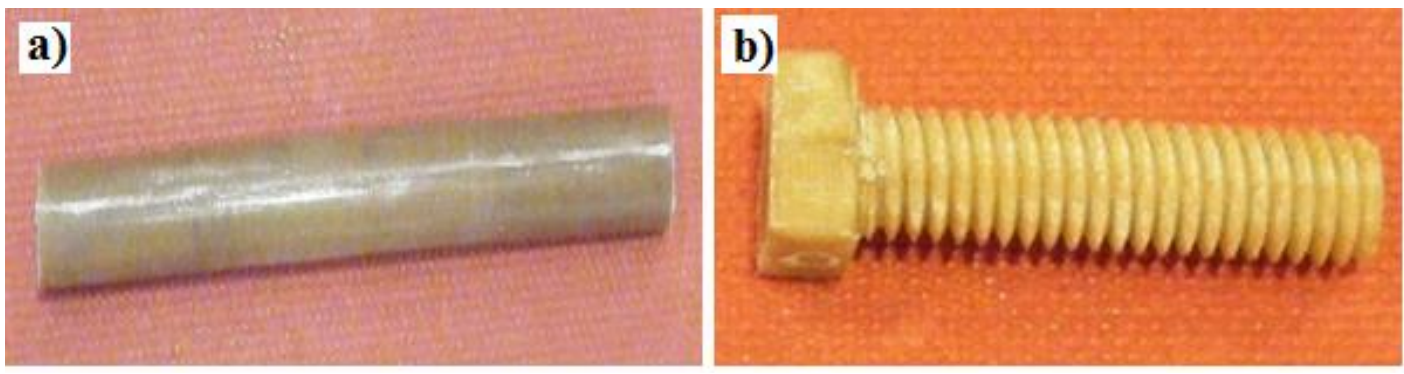

Figure 15: Images of a) composite rod, Adapted with permission from ${ }^{27}$ and b) composite screw prepared via the forging process. Adapted with permission from ${ }^{88}$.

An in vivo study conducted for PCL-PGF composites for 26 weeks used a rat calvarium model in order to provide information on the biocompatibility of the composite (which was designed for craniomaxillofacial reconstruction). No clinical complications were observed and all animals recovered well after surgery. A lack of inflammatory response was also observed from histological assessment. No bone was detected at the dural face of the implants up to the 4-week time point. Mineralised new bone was present at 8 weeks postsurgery for PCL, PCL-PGF and PCL-bioglass composites. Monolithic PCL did not support new bone formation, whilst PCL composite discs (see Figure 16a) showed a gradual increase in the amount of mineralised bone from 20 to 35 \% over time. At the 26 week time point, PCLPGF composites revealed a significantly greater quantity of new bone formation compared with PCL alone and PCL reinforced with $45 \mathrm{~S} 5$ bioglass fibres. Extensive bone growth was seen at 26 weeks which was examined using histological examination and micro-CT (see Figure $16 \mathrm{~b} \& \mathrm{c}){ }^{60}$. 
(a)

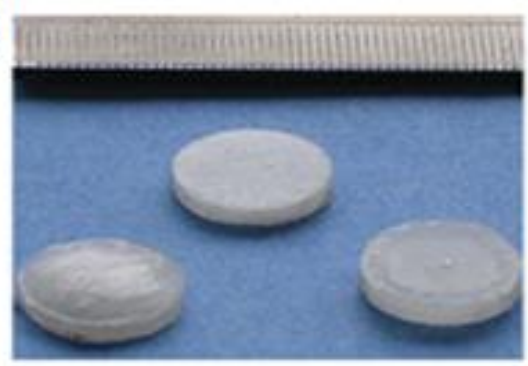

(c) (b)

PCL-PGF composites at 26 weeks

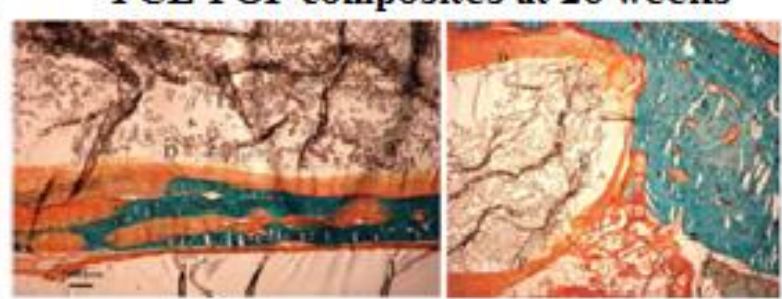

aPCL-PGF QPCL-bioglass

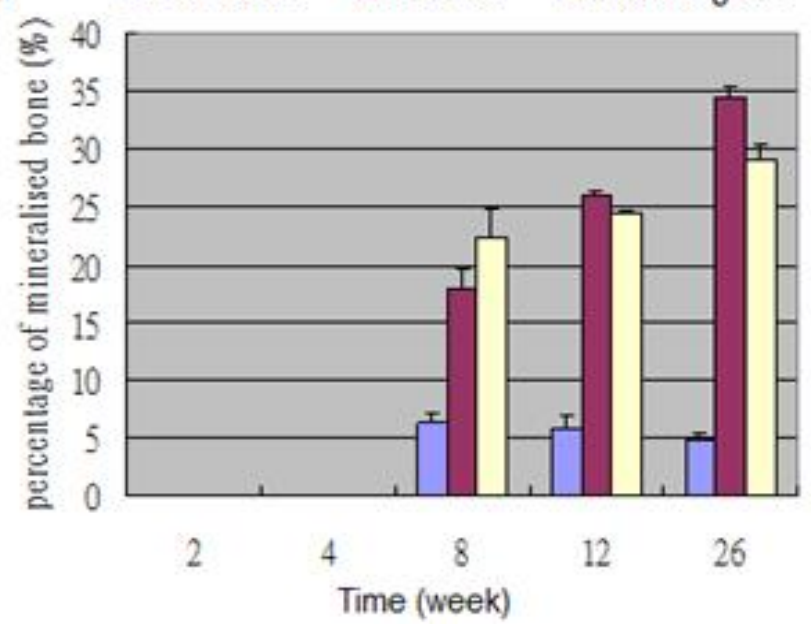

Figure 16: (a) PCL-phosphate glass discs before implantation ( $8 \mathrm{~mm}$ diameter), (b) examples of bone associated with the dural face of implants after 26 weeks implantation and (c) percentage of bone associated with the dural face of the implants for PCL, PCL-PGF and PCLbioglass composites. Adapted with permission from ${ }^{60}$.

\subsubsection{Dental applications}

PCL-PGF composites have also been investigated as root canal obturation materials and showed potential due to their capability of sealing in aqueous environments and releasing certain ions at controlled rates based on composition of PGF ${ }^{94}$. The amount of ions released was found to be inversely proportional to content of iron oxide within the glass composition. PCL-PGF composites revealed better adaptation in root canal than the conventional gutta-percha (GP) and adhered firmly to the canal wall (see Figure 17a). Strong adhesion with dentine was attributed to formation of precipitate along the entire canal wall. In contrast, a clear gap was detected between the dentine-GP interface (see Figure 17b) ${ }^{94}$. 

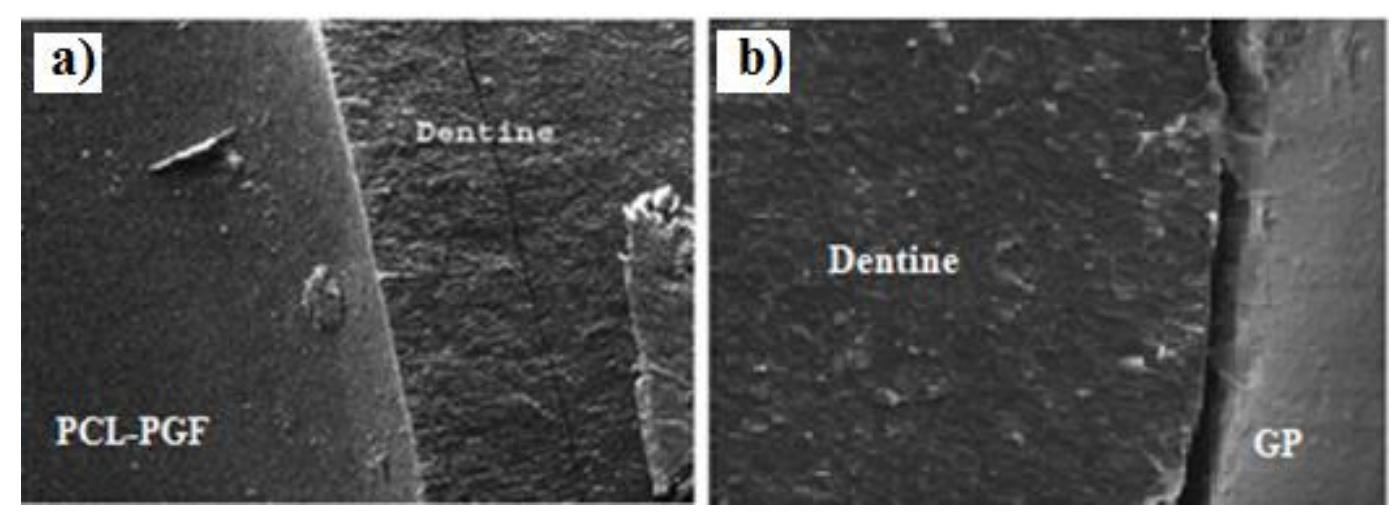

Figure 17: SEM micrographs for material filling-dentin interface; a) good adhesion can be seen between PCL-PGF composite and canal wall (magnification 900x) and b) a clear gap is present between gutta-percha (GP) and dentine at lower magnification (400x). Adapted with permission from ${ }^{94}$.

\subsubsection{Soft tissue repair}

Nazhat et al. ${ }^{95}$ produced spiral collagen scaffolds via incorporation of soluble UD PGF into dense collagen gels. They initially prepared sheets (50 $\mu \mathrm{m}$ thickness) of collagen-PGF UD composites via an unconfined plastic compression method and then rolled these composites sheets to form three-dimensional constructs. The mechanical properties of these scaffolds could be tuned by the amount of PGFs incorporated within. Tensile strength and modulus of the scaffolds increased to 2.3 and $165 \mathrm{MPa}$ respectively by inclusion of 30wt\% of PGF. Controlled degradation of PGF could enhance cell ingrowth, perfusion and integration of the scaffolds with the surrounding tissue. Joo et al. ${ }^{96}$ investigated the spiral collagen-PGF scaffolds as a potential candidate for axonal outgrowth following spinal cord injuries. They implanted cylindrical scaffolds into transected spinal cord of rats. The collagen-PGF scaffolds exhibited better performance compared to collagen alone and no inflammatory responses were observed for both groups. They concluded that these PGF incorporated constructs had potential for functional recovery of injured or even totally transected spinal cord in rats. 


\section{Conclusions and Outlook}

Different aspects of phosphate glass fibres and their composites, such as manufacturing processes, chemical composition and processing technique related properties (for example, dissolution, ion release and mechanical properties) for biomedical applications have been reviewed.

Compared to bulk glass, phosphate glass fibres possess many advantageous features, such as excellent mechanical properties, higher surface area, can enable greater reinforcing capability of polymer matrices and have also been explored as cell guides for soft tissue repair applications.

In addition, altering their chemical compositions and addition of modifier ions within the phosphate glass fibre structures, the strength of the chain forming bonds and the crosslinked networks within the glass structure could be controlled in order to manipulate the fibre degradation and mechanical properties required.

Applications of phosphate glass fibre alone spanning cell delivery vehicles, angiogenesis, nerve guides, antibacterial implants and scaffolds for regeneration of soft-hard tissue interface have all been investigated.

Phosphate glass fibre reinforced composite devices in the form of plates, rods, screws and scaffolds have shown to have vast potential with a wide range of mechanical properties for load bearing bone repair applications and for soft tissue repair applications. The fibre volume fraction, type, length, orientation of fibres (aligned or random) and strength of fibre/matrix interface had a significant influence on the mechanical performance of the composites produced.

Though, phosphate glass fibres and their composites have been investigated for varying biomedical applications due to their biocompatibilty, favourable degradation and mechanical properties, there still remain considerable developments to be achieved (for example, industrial fibre scale-up) in order to fully exploit these biomaterials for commercialisation. 
1. I. Ahmed, M. Lewis, I. Olsen and J. C. Knowles, Phosphate glasses for tissue engineering: Part 2. Processing and characterisation of a ternary-based P2O5-CaO-Na2O glass fibre system, Biomaterials, 2004, 25, 501-507.

2. I. Ahmed, M. Lewis, I. Olsen and J. C. Knowles, Phosphate glasses for tissue engineering: Part 1. Processing and characterisation of a ternary-based P2O5-CaO-Na2O glass system, Biomaterials, 2004, 25, 491-499.

3. J. C. Knowles, Phosphate based glasses for biomedical applications, Journal of Materials Chemistry, 2003, 13, 2395-2401.

4. X. Liu, D. M. Grant, G. Palmer, A. J. Parsons, C. D. Rudd and I. Ahmed, Magnesium coated phosphate glass fibers for unidirectional reinforcement of polycaprolactone composites, Journal of Biomedical Materials Research Part B: Applied Biomaterials, 2015, 103, 14241432.

5. I. Ahmed, C. A. Collins, M. P. Lewis, I. Olsen and J. C. Knowles, Processing, characterisation and biocompatibility of iron-phosphate glass fibres for tissue engineering, Biomaterials, 2004, 25, 3223-3232.

6. I. Ahmed, P. S. Cronin, E. A. Abou Neel, A. J. Parsons, J. C. Knowles and C. D. Rudd, Retention of mechanical properties and cytocompatibility of a phosphate-based glass fiber/polylactic acid composite, Journal of biomedical materials research. Part B, Applied biomaterials, 2009, 89, 18-27.

7. N. J. Lakhkar, J.-H. Park, N. J. Mordan, V. Salih, I. B. Wall, H.-W. Kim, S. P. King, J. V. Hanna, R. A. Martin, O. Addison, J. F. W. Mosselmans and J. C. Knowles, Titanium phosphate glass microspheres for bone tissue engineering, Acta Biomaterialia, 2012, 8, 4181-4190.

8. P. Haque, A. J. Parsons, I. A. Barker, I. Ahmed, D. J. Irvine, G. S. Walker and C. D. Rudd, Interfacial properties of phosphate glass fibres/PLA composites: Effect of the end functionalities of oligomeric PLA coupling agents, Composites Science and Technology, 2010, 70, 1854-1860.

9. I. Ahmed, A. Parsons, A. Jones, G. Walker, C. Scotchford and C. Rudd, Cytocompatibility and Effect of Increasing MgO Content in a Range of Quaternary Invert Phosphate-based Glasses, Journal of Biomaterials Applications, 2010, 24, 555-575.

10. I. Ahmed, I. Jones, A. Parsons, J. Bernard, J. Farmer, C. Scotchford, G. Walker and C. Rudd, Composites for bone repair: phosphate glass fibre reinforced PLA with varying fibre architecture, Journal of Materials Science: Materials in Medicine, 2011, 22, 1825-1834.

11. F. T. Wallenberger and N. E. Weston, Glass Fibers from High and Low Viscosity Melts, Mat Res Soc Symposium Proc, 2002, 702, 165-172.

12. F. T. Wallenberger, in Fiberglass and Glass Technology: Energy-Friendly Compositions and Applications, 2010, DOI: 10.1007/978-1-4419-0736-3_1, pp. 3-90.

13. J. Choueka, J. L. Charvet, H. Alexander, Y. O. Oh, G. Joseph, N. C. Blumenthal and W. C. LaCourse, Effect of annealing temperature on the degradation of reinforcing fibers for absorbable implants, J Biomed Mater Res, 1995, 29, 1309-1315.

14. D. Furniss and A. B. Seddon, Towards monomode proportioned fibreoptic preforms by extrusion, Journal of Non-Crystalline Solids, 1999, 256-257, 232-236.

15. I. Ahmed, S. S. Shaharuddin, N. Sharmin, D. Furniss and C. Rudd, Journal, 2015, 1.

16. S. Lee, A. Obata and T. Kasuga, Ion release from $\mathrm{SrO}_{-} \mathrm{CaO}-\mathrm{TiO}_{2}-\mathrm{P}_{2} \mathrm{O}_{5}$ glasses in Tris buffer solution, Journal of the Ceramic Society of Japan, 2009, 117, 935-938.

17. M. Navarro, M. P. Ginebra and J. A. Planell, Cellular response to calcium phosphate glasses with controlled solubility, J Biomed Mater Res A, 2003, 67, 1009-1015.

18. E. A. Abou Neel, I. Ahmed, J. J. Blaker, A. Bismarck, A. R. Boccaccini, M. P. Lewis, S. N. Nazhat and J. C. Knowles, Effect of iron on the surface, degradation and ion release properties of phosphate-based glass fibres, Acta Biomaterialia, 2005, 1, 553-563. 
19. F. Ungaro, R. d'Emmanuele di Villa Bianca, C. Giovino, A. Miro, R. Sorrentino, F. Quaglia and M. I. La Rotonda, Insulin-loaded PLGA/cyclodextrin large porous particles with improved aerosolization properties: In vivo deposition and hypoglycaemic activity after delivery to rat lungs, Journal of Controlled Release, 2009, 135, 25-34.

20. N. Mofidi, M. Aghai-Moghadam and M. N. Sarbolouki, Mass preparation and characterization of alginate microspheres, Process Biochemistry, 2000, 35, 885-888.

21. S. Ichihara, Y. Inada, A. Nakada, K. Endo, T. Azuma, R. Nakai, S. Tsutsumi, H. Kurosawa and T. Nakamura, Development of new nerve guide tube for repair of long nerve defects, Tissue engineering. Part C, Methods, 2009, 15, 387-402.

22. L. W. Chan, H. Y. Lee and P. W. S. Heng, Production of alginate microspheres by internal gelation using an emulsification method, International Journal of Pharmaceutics, 2002, 242, 259-262.

23. S. Tanaka, T. Takigawa, S. Ichihara and T. Nakamura, Mechanical properties of the bioabsorbable polyglycolic acid-collagen nerve guide tube, Polymer Engineering \& Science, 2006, 46, 1461-1467.

24. H. K. Kim, H. J. Chung and T. G. Park, Biodegradable polymeric microspheres with "open/closed" pores for sustained release of human growth hormone, Journal of Controlled Release, 2006, 112, 167-174.

25. Y. Yang, N. Bajaj, P. Xu, K. Ohn, M. D. Tsifansky and Y. Yeo, Development of highly porous large PLGA microparticles for pulmonary drug delivery, Biomaterials, 2009, 30, 1947-1953.

26. Y.-J. Maeng, S.-W. Choi, H. O. Kim and J.-H. Kim, Culture of human mesenchymal stem cells using electrosprayed porous chitosan microbeads, Journal of Biomedical Materials Research Part A, 2010, 92A, 869-876.

27. R. Felfel, I. Ahmed, A. Parsons, L. Harper and C. Rudd, Initial mechanical properties of phosphate-glass fibre-reinforced rods for use as resorbable intramedullary nails, Journal of Materials Science, 2012, 47, 4884-4894.

28. T. K. Kim, J. J. Yoon, D. S. Lee and T. G. Park, Gas foamed open porous biodegradable polymeric microspheres, Biomaterials, 2006, 27, 152-159.

29. M. Bitar, V. Salih, J. C. Knowles and M. P. Lewis, Iron-phosphate glass fiber scaffolds for the hard-soft interface regeneration: The effect of fiber diameter and flow culture condition on cell survival and differentiation, Journal of Biomedical Materials Research Part A, 2008, 87A, 1017-1026.

30. T. Kiyotani, M. Teramachi, Y. Takimoto, T. Nakamura, Y. Shimizu and K. Endo, Nerve regeneration across a 25-mm gap bridged by a polyglycolic acid-collagen tube: a histological and electrophysiological evaluation of regenerated nerves, Brain Research, 1996, 740, 66-74.

31. R. Shah, A. C. M. Sinanan, J. C. Knowles, N. P. Hunt and M. P. Lewis, Craniofacial muscle engineering using a 3-dimensional phosphate glass fibre construct, Biomaterials, 2005, 26, 1497-1505.

32. C. Vitale-Brovarone, G. Novajra, J. Lousteau, D. Milanese, S. Raimondo and M. Fornaro, Phosphate glass fibres and their role in neuronal polarization and axonal growth direction, Acta Biomaterialia, 2012, 8, 1125-1136.

33. E. A. Abou Neel, I. Ahmed, J. Pratten, S. N. Nazhat and J. C. Knowles, Characterisation of antibacterial copper releasing degradable phosphate glass fibres, Biomaterials, 2005, 26, 2247-2254.

34. G. Lundborg, L. B. Dahlin, N. Danielsen, R. H. Gelberman, F. M. Longo, H. C. Powell and S. Varon, Nerve regeneration in silicone chambers: Influence of gap length and of distal stump components, Experimental Neurology, 1982, 76, 361-375.

35. J. E. Bergsma, W. C. de Bruijn, F. R. Rozema, R. R. M. Bos and G. Boering, Late degradation tissue response to poly(L-lactide) bone plates and screws, Biomaterials, 1995, 16, 25-31. 
36. M. Bühler, P.-E. Bourban and J.-A. E. Månson, Cellular composites based on continuous fibres and bioresorbable polymers, Composites Part A: Applied Science and Manufacturing, 2008, 39, 1779-1786.

37. A. Weiler, R. F. G. Hoffmann, A. C. Stahelin, H.-J. Helling and N. P. Sudkamp, Biodegradable implants in sports medicine: The biological base, Arthroscopy: The Journal of Arthroscopic \&amp; Related Surgery, 2000, 16, 305-321.

38. S. Fu, X. Feng, B. Lauke and Y.-W. Mai, Effects of particle size, particle/matrix interface adhesion and particle loading on mechanical properties of particulate-polymer composites, Composites Part B: Engineering, 2008, 39, 933-961.

39. D. F. Williams, The Williams dictionary of biomaterials, Liverpool University Press, Liverpool, 1999.

40. S. Ramakrishna, J. Mayer, E. Wintermantel and K. W. Leong, Biomedical applications of polymer-composite materials: a review, Composites Science and Technology, 2001, 61, 11891224.

41. I. Ahmed, P. S. Cronin, E. A. Abou Neel, A. J. Parsons, J. C. Knowles and C. D. Rudd, Retention of mechanical properties and cytocompatibility of a phosphate-based glass fiber/polylactic acid composite, Journal of Biomedical Materials Research Part B: Applied Biomaterials, 2009, 89B, 18-27.

42. W. Bonfield, Hydroxyapatite-Reinforced Polyethylene as an Analogous Material for Bone Replacementa, Annals of the New York Academy of Sciences, 1988, 523, 173-177.

43. Y. Z. Wan, Y. L. Wang, X. H. Xu and Q. Y. Li, In vitro degradation behavior of carbon fiberreinforced PLA composites and influence of interfacial adhesion strength, Journal of Applied Polymer Science, 2001, 82, 150-158.

44. C. Zimmerman Mark, H. Alexander, J. R. Parsons and P. K. Bajpai, in High-Tech Fibrous Materials, American Chemical Society, 1991, vol. 457, pp. 132-148.

45. G. Jiang, M. E. Evans, I. A. Jones, C. D. Rudd, C. A. Scotchford and G. S. Walker, Preparation of poly([epsilon]-caprolactone)/continuous bioglass fibre composite using monomer transfer moulding for bone implant, Biomaterials, 2005, 26, 2281-2288.

46. Y. Han, D. Radziuk, D. Shchukin and H. Moehwald, Stability and size dependence of protein microspheres prepared by ultrasonication, Journal of Materials Chemistry, 2008, 18, 51625166.

47. S. L. Evans and P. J. Gregson, Composite technology in load-bearing orthopaedic implants, Biomaterials, 1998, 19, 1329-1342.

48. D. Hull and T. W. Clyne, An Introduction to Composite Materials Cambridge, 1981.

49. P. A. Smith and J. A. Yeomans, in MATERIAL SCIENCE AND ENGINEERING, ed. R. D. Rawlings, 2009, vol. II, pp. 133 - 154.

50. G. R. D. Evans, K. Brandt, M. S. Widmer, L. Lu, R. K. Meszlenyi, P. K. Gupta, A. G. Mikos, J. Hodges, J. Williams, A. Gürlek, A. Nabawi, R. Lohman and C. W. Patrick Jr, In vivo evaluation of poly(I-lactic acid) porous conduits for peripheral nerve regeneration, Biomaterials, 1999, 20, 1109-1115.

51. E. Pirhonen and P. Törmälä, Coating of bioactive glass 13-93 fibres with biomedical polymers, Journal of Materials Science, 2006, 41, 2031-2036.

52. A. D. D. Matilde, J. C. Nichola and L. H. Larry, Tensile properties of bioactive fibers for tissue engineering applications, Journal of Biomedical Materials Research, 2000, 53, 199-203.

53. H. W. Kim, H. E. Kim and J. C. Knowles, Production and Potential of Bioactive Glass Nanofibers as a Next-Generation Biomaterial, Advanced Functional Materials, 2006, 16, 1529-1535.

54. E. Pirhonen, H. Niiranen, T. Niemelä, M. Brink and P. Törmälä, Manufacturing, mechanical characterization, and </>in vitro</1> performance of bioactive glass 13-93 fibers, Journal of Biomedical Materials Research Part B: Applied Biomaterials, 2006, 77B, 227-233. 
55. A. R. Boccaccini and V. Maquet, Bioresorbable and bioactive polymer/Bioglass ${ }^{\circledR}$ composites $^{2}$ with tailored pore structure for tissue engineering applications, Composites Science and Technology, 2003, 63, 2417-2429.

56. A. R. Boccaccini, M. Erol, W. J. Stark, D. Mohn, Z. Hong and J. F. Mano, Polymer/bioactive glass nanocomposites for biomedical applications: A review, Composites Science and Technology, 2010, 70, 1764-1776.

57. D. Brauer, C. Rüssel, S. Vogt, J. Weisser and M. Schnabelrauch, Degradable phosphate glass fiber reinforced polymer matrices: mechanical properties and cell response, Journal of Materials Science: Materials in Medicine, 2008, 19, 121-127.

58. A. J. Parsons, I. Ahmed, P. Haque, B. Fitzpatrick, M. I. K. Niazi, G. S. Walker and C. D. Rudd, Phosphate Glass Fibre Composites for Bone Repair, Journal of Bionic Engineering, 2009, 6, 318-323.

59. S. Lin, S. Krebs, A. Nazre and R. King, presented in part at the 39th International SAMPE Symposium, April 11-14, 1994.

60. C. A. Scotchford, M. Shataheri, P. S. Chen, M. Evans, A. J. Parsons, G. A. Aitchison, C. Efeoglu, J. L. Burke, A. Vikram, S. E. Fisher and C. D. Rudd, Repair of calvarial defects in rats by prefabricated, degradable, long fibre composite implants, J Biomed Mater Res A, 2010, 96, 230-238.

61. I. Ahmed, I. Jones, A. Parsons, J. Bernard, J. Farmer, C. Scotchford, G. Walker and C. Rudd, Composites for bone repair: phosphate glass fibre reinforced PLA with varying fibre architecture, Journal of Materials Science: Materials in Medicine, 2011, 22, 1825 - 1834.

62. J. L. Charvet, J. A. Cordes and H. Alexander, Mechanical and fracture behavior of a fiberreinforced bioabsorbable material for orthopaedic applications, Journal of Materials Science: Materials in Medicine, 2000, 11, 101-109.

63. P. Borbely, K. Gulabivala and J. C. Knowles, Degradation properties and ion release characteristics of Resilon and phosphate glass/polycaprolactone composites, Int Endod J, 2008, 41, 1093-1100.

64. W. S. DePolo and D. G. Baird, Particulate reinforced PC/PBT composites. I. Effect of particle size (nanotalc versus fine talc particles) on dimensional stability and properties, Polymer Composites, 2009, 30, 188-199.

65. S. K. De and J. R. White, Short Fibre-Polymer Composites, Woodhead Publishing, 1996.

66. R. Krüger and J. Groll, Fiber reinforced calcium phosphate cements - On the way to degradable load bearing bone substitutes?, Biomaterials, 2012, 33, 5887-5900.

67. R. M. Felfel, I. Ahmed, A. J. Parsons, P. Haque, G. S. Walker and C. D. Rudd, Investigation of Crystallinity, Molecular Weight Change, and Mechanical Properties of PLA/PBG Bioresorbable Composites as Bone Fracture Fixation Plates, J Biomater Appl, 2012, 26, 765 789.

68. M. Hasan, I. Ahmed, A. Parsons, G. Walker and C. Scotchford, Cytocompatibility and Mechanical Properties of Short Phosphate Glass Fibre Reinforced Polylactic Acid (PLA) Composites: Effect of Coupling Agent Mediated Interface, Journal of Functional Biomaterials, 2012, 3, 706.

69. X. Liu, M. S. Hasan, D. M. Grant, L. T. Harper, A. J. Parsons, G. Palmer, C. D. Rudd and I. Ahmed, Mechanical, degradation and cytocompatibility properties of magnesium coated phosphate glass fibre reinforced polycaprolactone composites, Journal of Biomaterials Applications, 2014, 29, 675-687.

70. L. T. Harper, I. Ahmed, R. M. Felfel and C. Qian, Finite element modelling of the flexural performance of resorbable phosphate glass fibre reinforced PLA composite bone plates, Journal of the Mechanical Behavior of Biomedical Materials, 2012, 15, 13-23.

71. A. J. Parsons, I. Ahmed, N. Han, R. Felfel and C. D. Rudd, Mimicking Bone Structure and Function with Structural Composite Materials, Journal of Bionic Engineering, 2010, 7, S1-S10. 
72. K. P. Andriano, A. U. Daniels and J. Heller, Biocompatibility and mechanical properties of a totally absorbable composite material for orthopaedic fixation devices, Journal of Applied Biomaterials, 1992, 3, 197-206.

73. M. S. Hasan, I. Ahmed, A. J. Parsons, G. S. Walker and C. A. Scotchford, The influence of coupling agents on mechanical property retention and long-term cytocompatibility of phosphate glass fibre reinforced PLA composites, Journal of the Mechanical Behavior of Biomedical Materials, 2013, 28, 1-14.

74. R. A. Khan, A. J. Parsons, I. A. Jones, G. S. Walker and C. D. Rudd, Effectiveness of 3Aminopropyl-Triethoxy-Silane as a Coupling Agent for Phosphate Glass Fiber-Reinforced Poly(caprolactone)-based Composites for Fracture Fixation Devices, Journal of Thermoplastic Composite Materials, 2011, 24, 517-534.

75. R. A. Khan, A. J. Parsons, I. A. Jones, G. S. Walker and C. D. Rudd, Surface treatment of phosphate glass fibers using 2-hydroxyethyl methacrylate: Fabrication of poly(caprolactone)based composites, Journal of Applied Polymer Science, 2009, 111, 246-254.

76. R. A. Khan, A. J. Parsons, I. A. Jones, G. S. Walker and C. D. Rudd, Degradation and Interfacial Properties of Iron Phosphate Glass Fiber-Reinforced PCL-Based Composite for Synthetic Bone Replacement Materials, Polymer-Plastics Technology and Engineering, 2010, 49, 1265-1274.

77. X. Liu, D. M. Grant, G. Palmer, A. J. Parsons, C. D. Rudd and I. Ahmed, Magnesium coated phosphate glass fibers for unidirectional reinforcement of polycaprolactone composites, Journal of Biomedical Materials Research Part B: Applied Biomaterials, 2014, DOI: 10.1002/jbm.b.33324, n/a-n/a.

78. M. S. Mohammadi, I. Ahmed, N. Muja, S. Almeida, C. D. Rudd, M. N. Bureau and S. N. Nazhat, Effect of $\mathrm{Si}$ and $\mathrm{Fe}$ doping on calcium phosphate glass fibre reinforced polycaprolactone bone analogous composites, Acta Biomater, 2012, 8, 1616-1626.

79. U. Koichiro, M. Takanari, O. Michio, T. Hiroyuki, M. Tsuyoshi, E. Mitsuhiro and A. Takao, Design of super-elastic biodegradable scaffolds with longitudinally oriented microchannels and optimization of the channel size for Schwann cell migration, Science and Technology of Advanced Materials, 2012, 13, 064207.

80. R. M. Felfel, I. Ahmed, A. J. Parsons, G. S. Walker and C. D. Rudd, In vitro degradation, flexural, compressive and shear properties of fully bioresorbable composite rods, Journal of the Mechanical Behavior of Biomedical Materials, 2011, 4, 1462-1472.

81. R. M. Felfel, I. Ahmed, A. J. Parsons, G. Palmer, V. Sottile and C. D. Rudd, Cytocompatibility, degradation, mechanical property retention and ion release profiles for phosphate glass fibre reinforced composite rods, Materials Science and Engineering: C, 2013, 33, 1914-1924.

82. P. Haque, I. A. Barker, A. Parsons, K. J. Thurecht, I. Ahmed, G. S. Walker, C. D. Rudd and D. J. Irvine, Influence of compatibilizing agent molecular structure on the mechanical properties of phosphate glass fiber-reinforced PLA composites, Journal of Polymer Science Part A: Polymer Chemistry, 2010, 48, 3082-3094.

83. M. S. Hasan, I. Ahmed, A. J. Parsons, C. D. Rudd, G. S. Walker and C. A. Scotchford, Investigating the use of coupling agents to improve the interfacial properties between a resorbable phosphate glass and polylactic acid matrix, Journal of Biomaterials Applications, 2013, 28, 354-366.

84. L. Onal, S. Cozien-Cazuc, I. A. Jones and C. D. Rudd, Water absorption properties of phosphate glass fiber-reinforced poly-e-caprolactone composites for craniofacial bone repair, Journal of Applied Polymer Science, 2008, 107, 3750-3755.

85. X. Liu, D. M. Grant, A. J. Parsons, L. T. Harper, C. D. Rudd and I. Ahmed, Magnesium Coated Bioresorbable Phosphate Glass Fibres: Investigation of the Interface between Fibre and Polyester Matrices, BioMed Research International, 2013, 2013, 10.

86. N. Han, I. Ahmed, A. J. Parsons, L. Harper, C. A. Scotchford, B. E. Scammell and C. D. Rudd, Influence of screw holes and gamma sterilization on properties of phosphate glass fiberreinforced composite bone plates, J Biomater Appl, 2011, DOI: 0885328211431855 [pii] 
10.1177/0885328211431855.

87. R. Felfel, I. Ahmed, A. Parsons, G. Walker and C. Rudd, Flexural, Shear and Compressive Properties of Bioresorbable PLA-PBG Fibre Reinforced Composite Intramedullary Rods, World Journal of Engineering, 2010, 323 - 324.

88. R. M. Felfel, I. Ahmed, A. J. Parsons and C. D. Rudd, Bioresorbable screws reinforced with phosphate glass fibre: Manufacturing and mechanical property characterisation, Journal of the Mechanical Behavior of Biomedical Materials, 2013, 17, 76-88.

89. R. M. Felfel, I. Ahmed, A. J. Parsons and C. D. Rudd, Bioresorbable composite screws manufactured via forging process: Pull-out, shear, flexural and degradation characteristics, Journal of the Mechanical Behavior of Biomedical Materials, 2013, 18, 108-122.

90. R. M. Felfel, I. Ahmed, A. J. Parsons, G. S. Walker and C. D. Rudd, In vitro degradation, flexural, compressive and shear properties of fully bioresorbable composite rods, Journal of the Mechanical Behavior of Biomedical Materials, 2011, 4, 1462 - 1472.

91. H. Cai, V. Dave, R. A. Gross and S. P. McCarthy, Effects of physical aging, crystallinity, and orientation on the enzymatic degradation of poly(lactic acid), Journal of Polymer Science Part B: Polymer Physics, 1996, 34, 2701-2708.

92. Y. Tokiwa, B. Calabia, C. Ugwu and S. Aiba, Biodegradability of Plastics, International Journal of Molecular Sciences, 2009, 10, 3722-3742.

93. Q. Zhou and M. Xanthos, Nanoclay and crystallinity effects on the hydrolytic degradation of polylactides, Polymer Degradation and Stability, 2008, 93, 1450-1459.

94. A. Alani, J. C. Knowles, W. Chrzanowski, Y. L. Ng and K. Gulabivala, Ion release characteristics, precipitate formation and sealing ability of a phosphate glass-polycaprolactone-based composite for use as a root canal obturation material, Dent Mater, 2009, 25, 400-410.

95. S. N. Nazhat, E. A. Abou Neel, A. Kidane, I. Ahmed, C. Hope, M. Kershaw, P. D. Lee, E. Stride, N. Saffari, J. C. Knowles and R. A. Brown, Controlled Microchannelling in Dense Collagen Scaffolds by Soluble Phosphate Glass Fibers, Biomacromolecules, 2007, 8, 543-551.

96. N.-Y. Joo, J. C. Knowles, G.-S. Lee, J.-W. Kim, H.-W. Kim, Y.-J. Son and J. K. Hyun, Effects of phosphate glass fiber-collagen scaffolds on functional recovery of completely transected rat spinal cords, Acta Biomaterialia, 2012, 8, 1802-1812. 